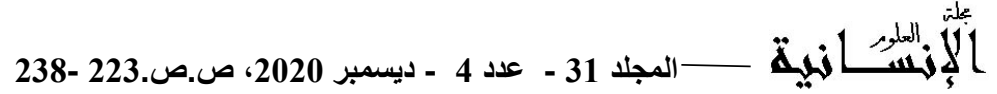

\section{خصوصية الثركة الرياضية التجارية عند التأسيس}

The particularity of Commercial Sports Company at founding. تاريخ الاستلام: 2020/03/06؛ تاريخ القبول: 2020/11/17

\begin{tabular}{|c|c|}
\hline & 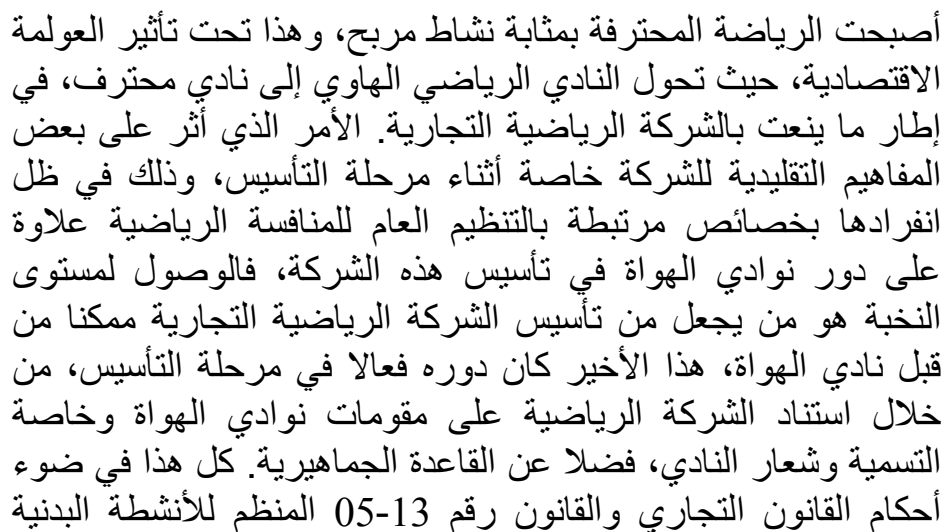 \\
\hline 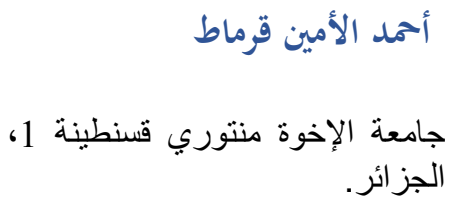 & 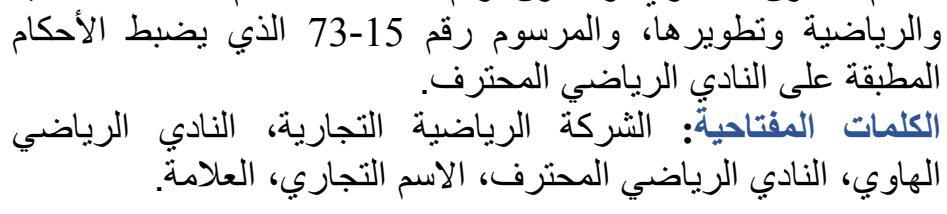 \\
\hline
\end{tabular}

\section{Abstract}

Professional sport has become a profitable activity, under the influence of economic globalization. The amateur sports club has become a professional club. As part of what is called the commercial sports company. which affected some of the traditional concepts of the association, especially during the establishment phase. This is in particular due to the characteristics associated with the general organization of sports competition as well as the role of amateur clubs in this society. It is the elite which makes possible the creation of the commercial sports company by the amateur club. If the role is effective at the founding phase, the sports society will base its contributions on the foundations of the amateur club through the club's name or slogan, as well as on the popular basis. All this in the light of the laws governing this matter, in particular the provisions of the Commercial Code, and Law No. 13-05 regulating and developing physical and sporting activities, and the Decree No. 15-73 regulating the provisions applicable to the club professional athlete.

Keywords: Commercial Sports Company, Amateur Sports Club, Professional Club, Trade Name, Trademark.

\section{Résumé}

Le sport professionnel est devenu une activité rentable, sous l'influence de la mondialisation économique. Le club de sport amateur est devenu un club professionnel. Dans le cadre de ce que l'on appelle la société sportive commerciale. qui a affecté certains des concepts traditionnels de l'association, en particulier pendant la phase d'établissement. Ceci est notamment dû aux caractéristiques associées à l'organisation générale de la compétition sportive ainsi qu'au rôle des clubs amateurs dans cette société. C'est l'élite qui rend possible la création de la société sportive commerciale par le club amateur. Si le rôle est efficace au phase de fondation, la société sportive fondera ses contributions sur les fondements du club amateur par le biais de la dénomination ou du slogan du club, ainsi que sur la base populaire. Tout cela à la lumière des lois régissant cette matière, notamment les dispositions du Code de Commerce, et la loi $\mathrm{n}^{\circ}$ 13-05 réglementant et développant les activités physiques et sportives, et le décret $\mathrm{n}^{\circ} 15-73$ réglementant les dispositions applicables au club sportif professionnel.

Mots clés : La Société Sportive Commerciale, Le Club de Sport Amateur, Club Professionnel, Le Nom Commercial, la Marque Déposée.

* Corresponding author, e-mail: ahmedelamineguermat@gmail.com 
I - I

لقد أدت ضرورة الاحتر اف الرياضي إلى بروز صنف جديد من أصناف الشركات

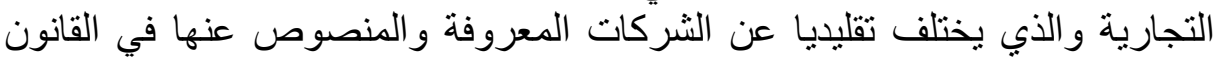

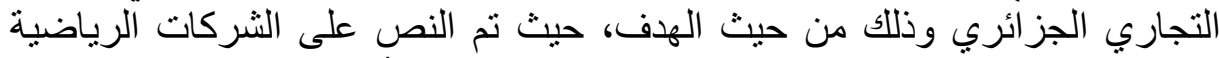

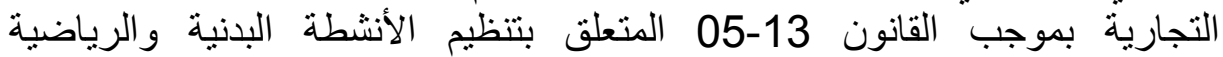

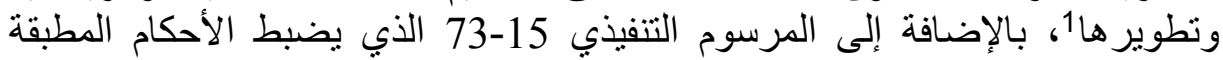

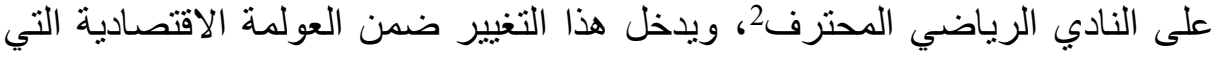

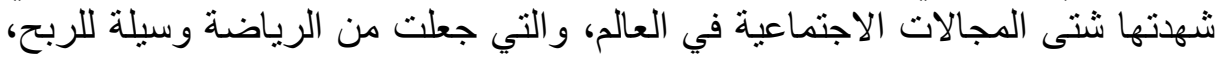

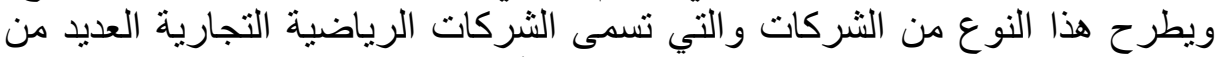

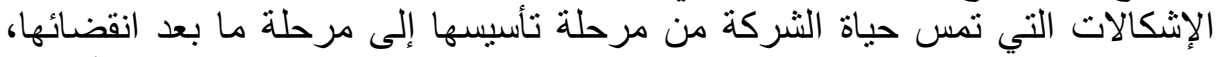

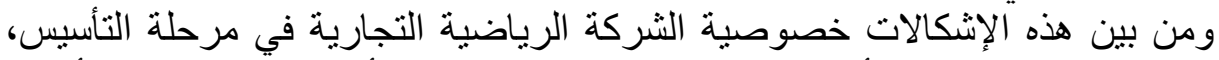

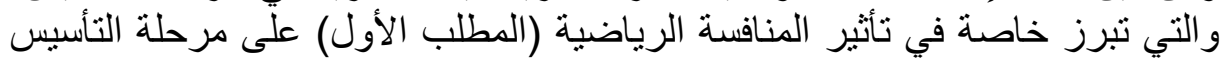
ودور النادي الرياضي الثركة، الهاوي الذي يخضي لنّع لقانون لجمعيات (المطلب الثناني) في هذه المرحلة من مر احل حياة.

\section{المطلب الأول: تأثير نظام المنافسة الرياضية على تأسيس الثركة الرياضية}

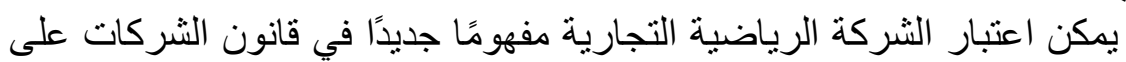

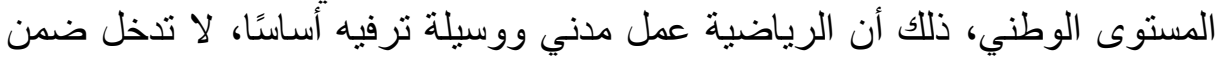

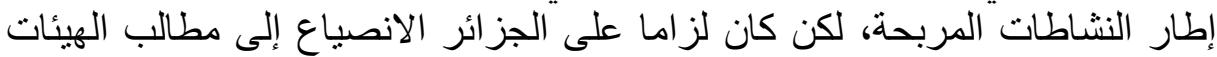

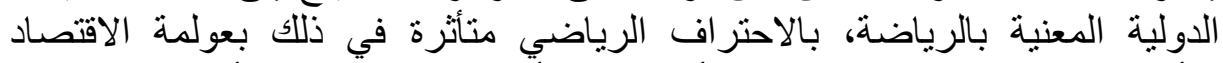

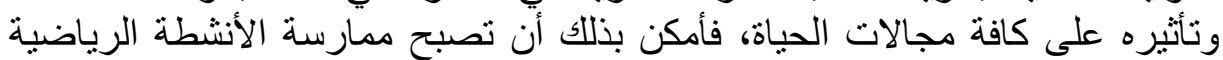

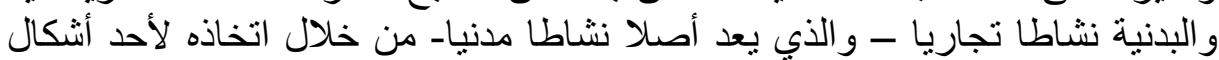

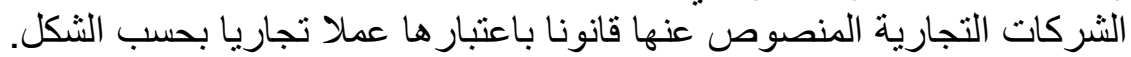

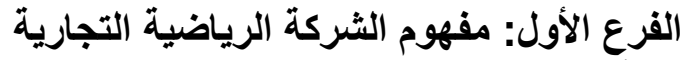

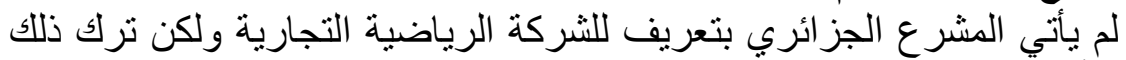

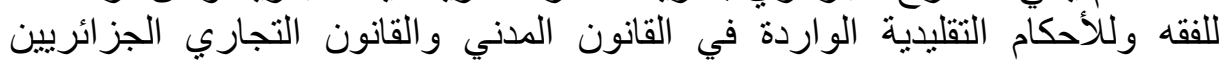

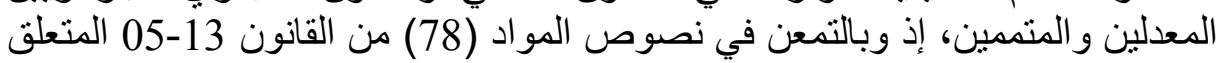

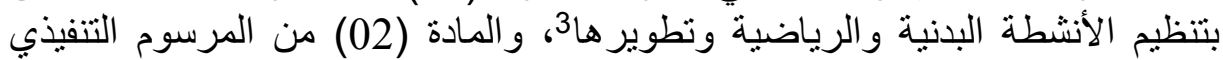

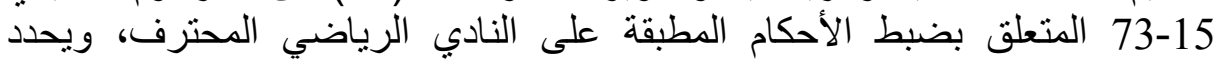

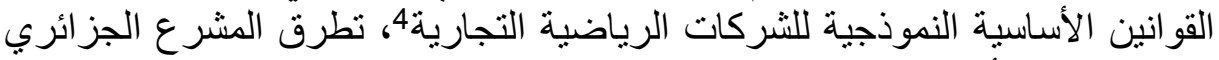

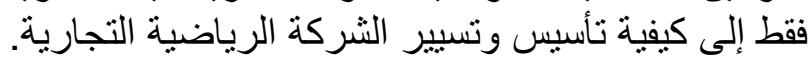

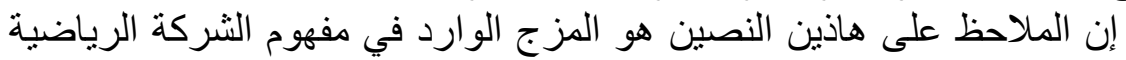
التجارية و النادي الرياضي المحترف هاذين النئ.

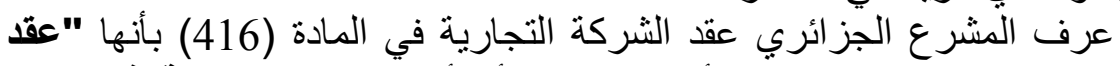

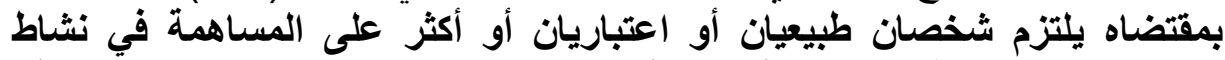

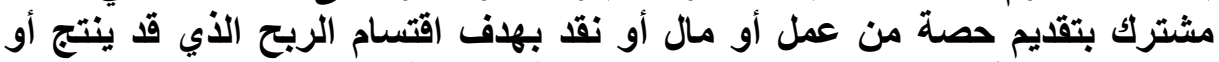

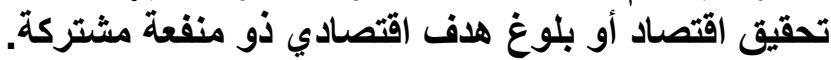

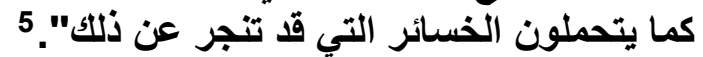

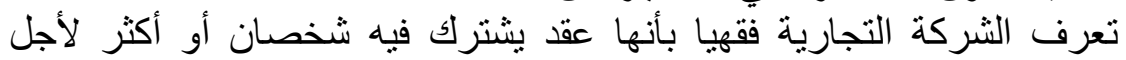

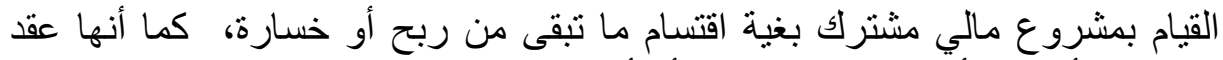

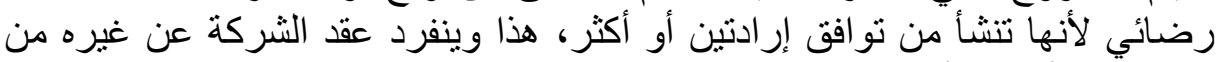

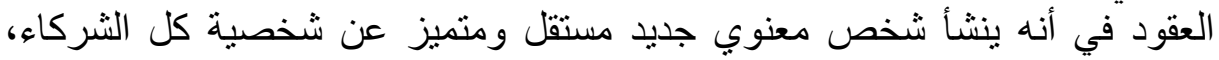

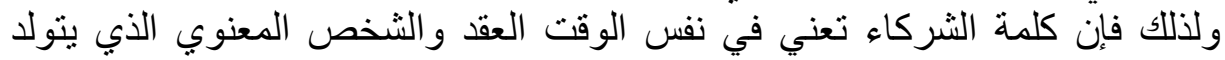




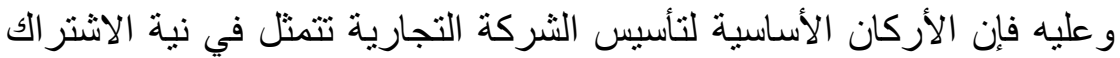

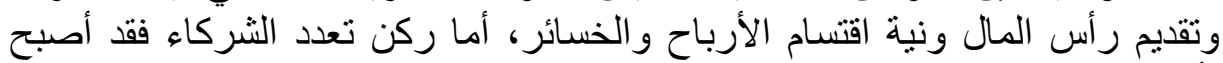

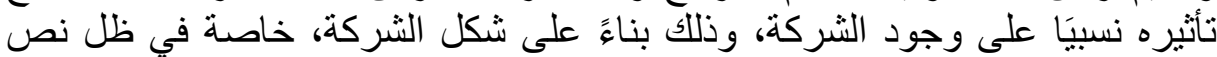

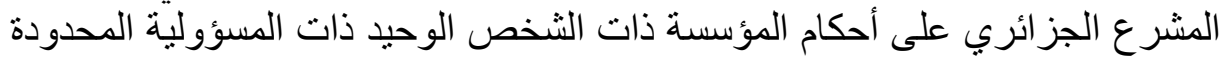

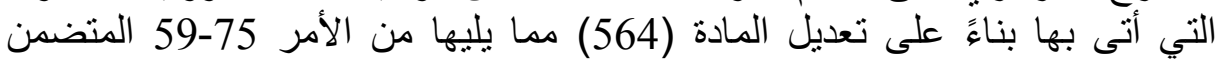

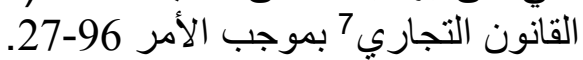

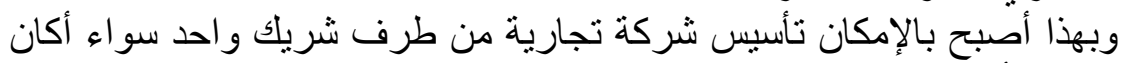

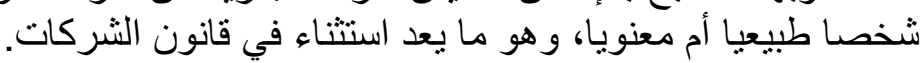

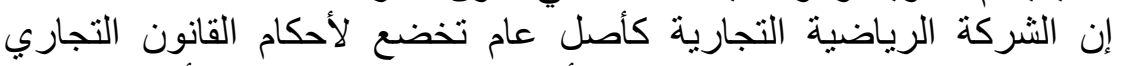

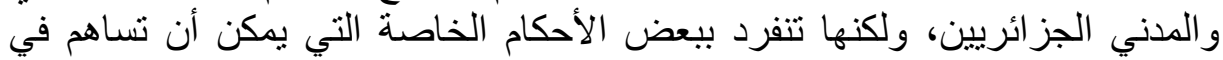

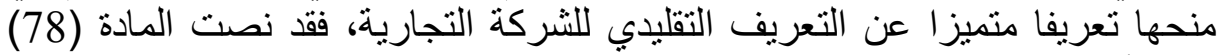

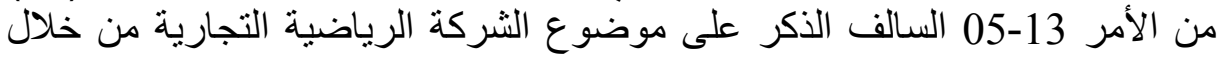

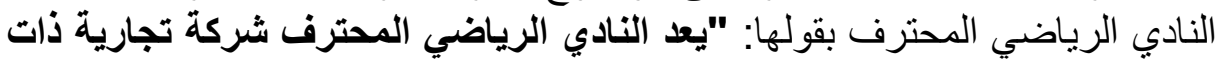

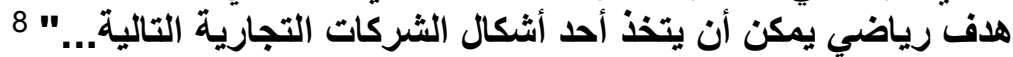

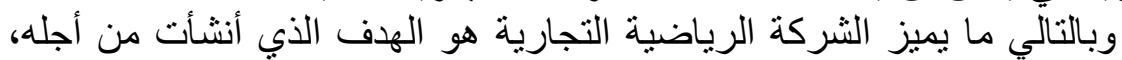

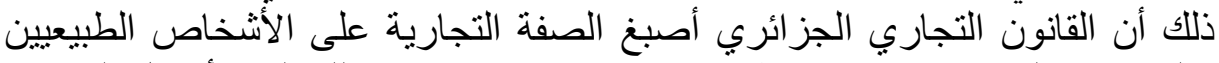

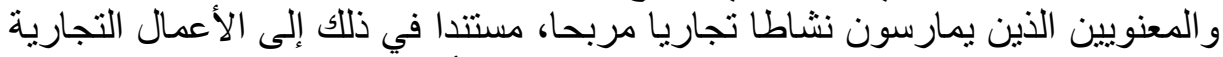
بحسب الموضوع حسب نص المادة (02) من الأمر

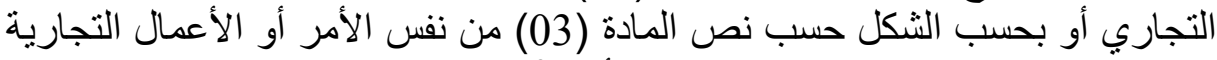
بالتبعية حسب التص بـ المادة (04) من نفس الأمر.

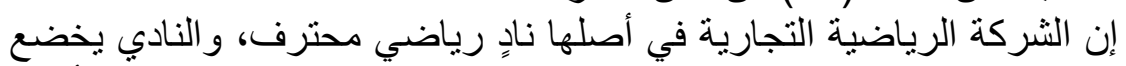

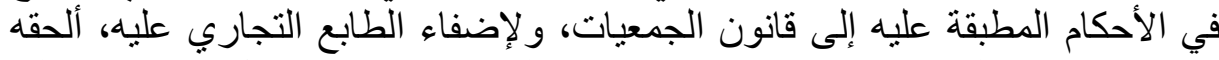

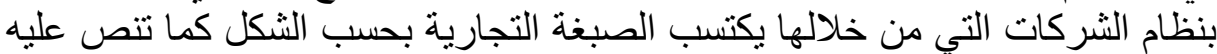

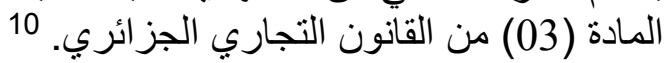

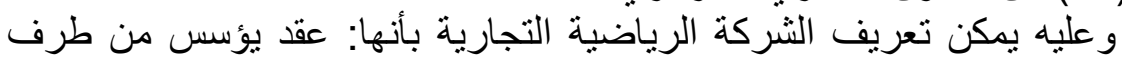

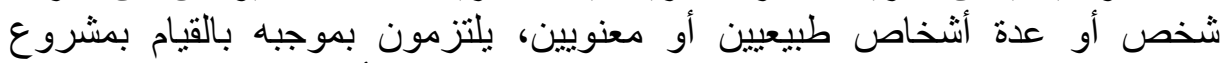

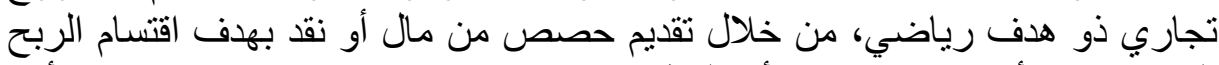

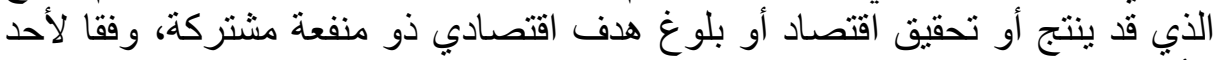

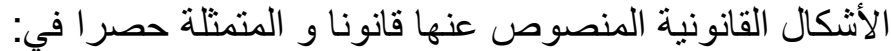

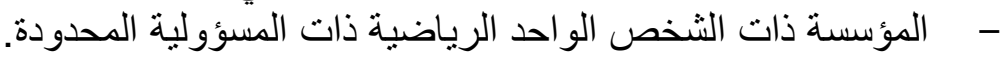

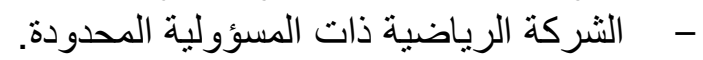

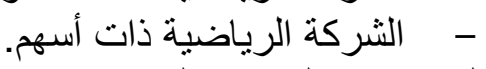

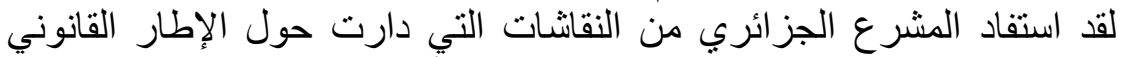

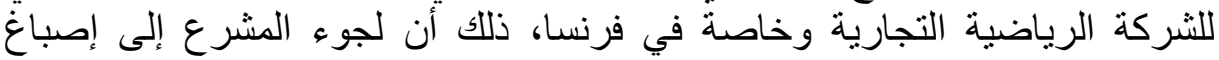

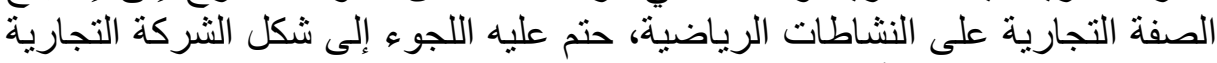

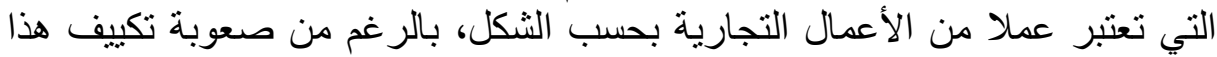

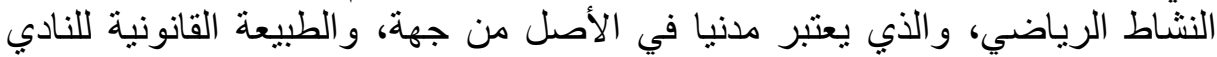

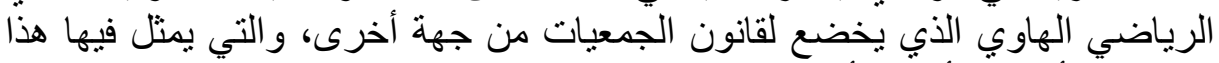
النادي في أغلب الأحوال أساس الثركة الرياضية التجانية التهية

الفرع الثاني: وجوب التأسيس مرتبط بالمنافسة الرياضية

يختلف نظام الهواة على نظام الاحتر اف في الرياضة، ذلك الك أن النادي الرياضي

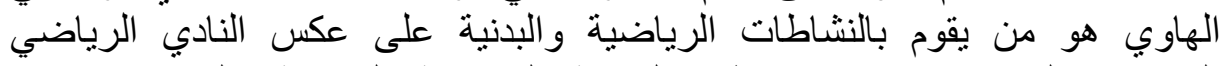

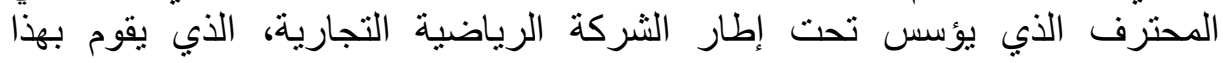




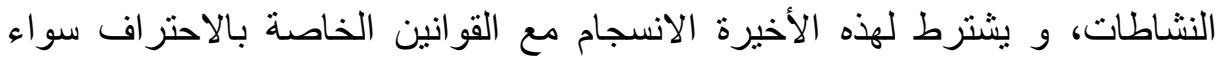

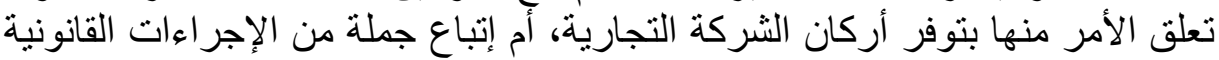

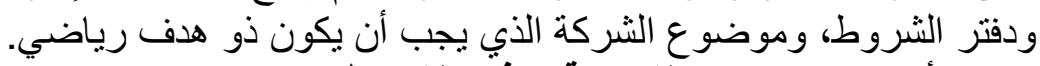

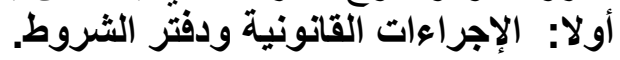

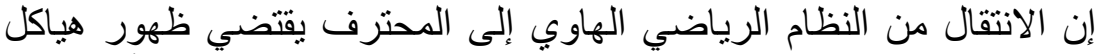

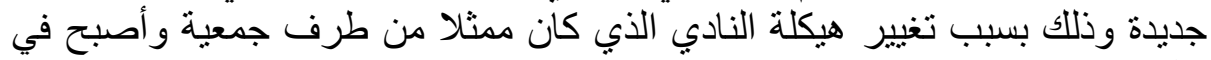

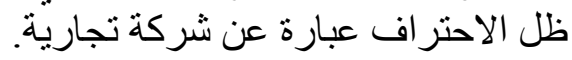

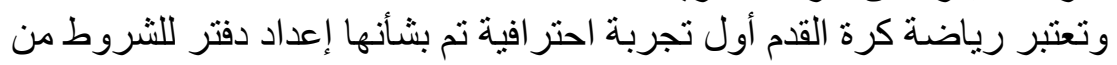

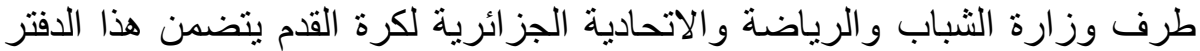

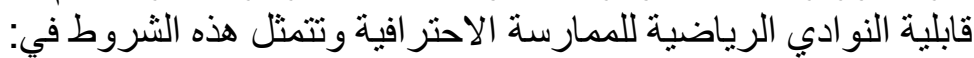
1- طنب التأهيل: (Demande D'habilitation) التعهد" في إطار دفتر الشروط نجد فيه مصطلحين وهما طلب" التأهيل "و" طلب

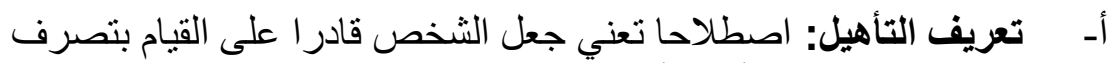

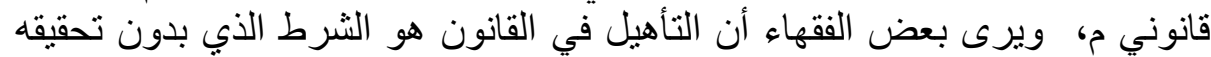
تكون ممارسة بعض النشاطات ممنوعة للأشخاص الخاصة. فالتأهيل يحدد كيفيات تدخل الخواص والثروط التي يجب أن تتدخل ضمن الأهداف المرجوة الوسائل

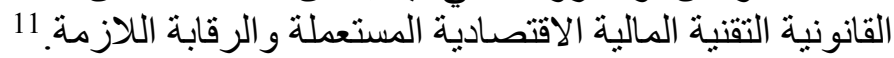

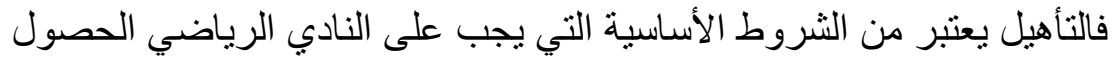

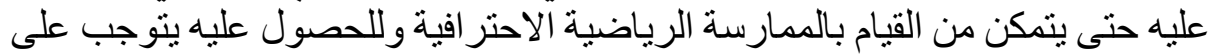

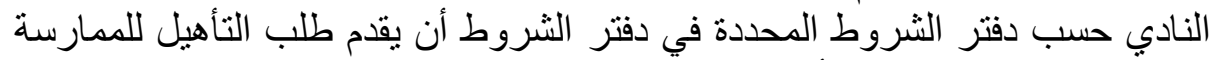

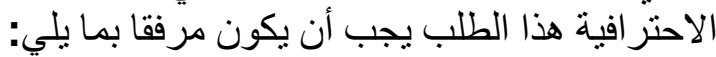

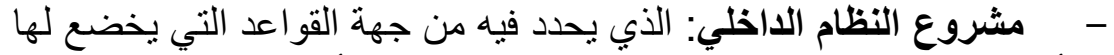

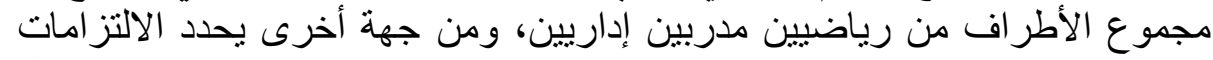

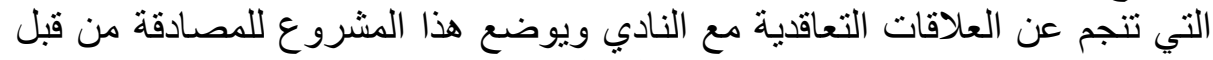

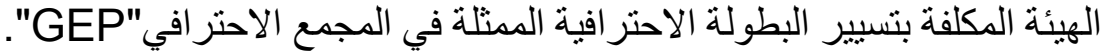

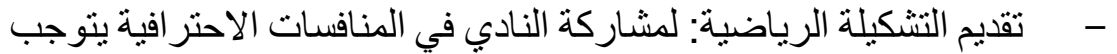

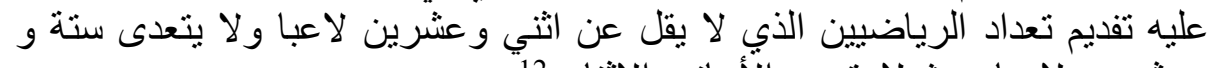
و عشرون لاعبا حيث لا يتعدى الأجانب الاثنان. 12

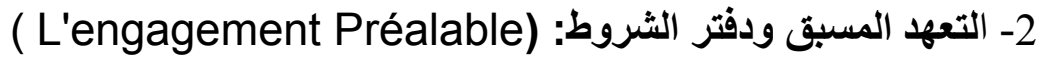

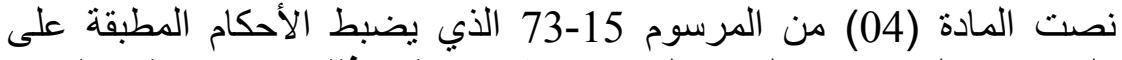

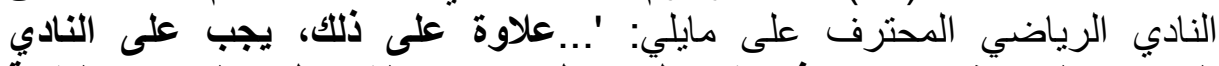

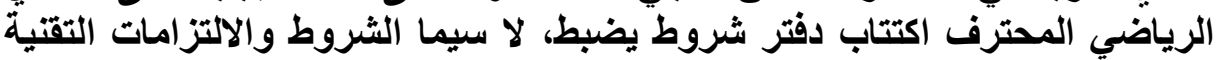

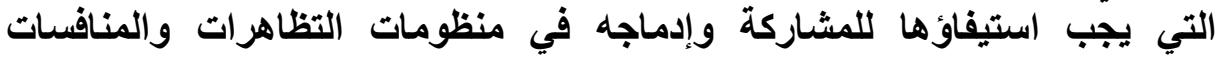

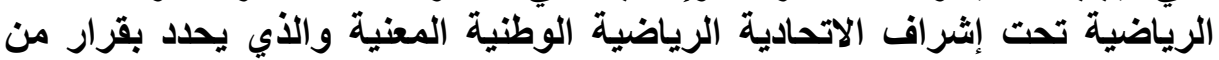

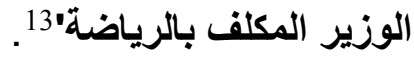

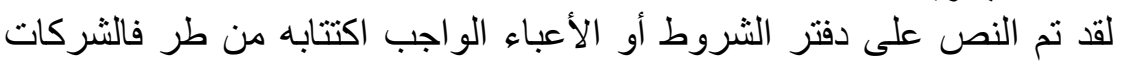

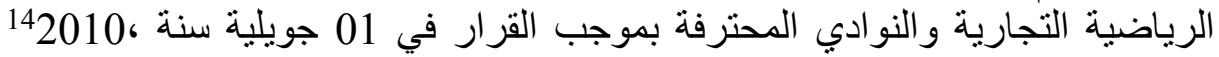

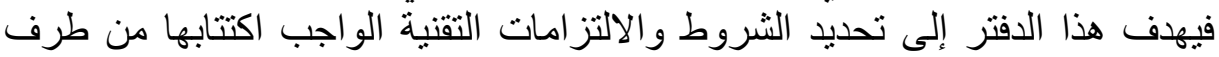

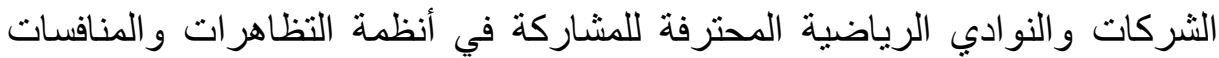

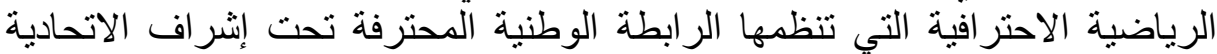

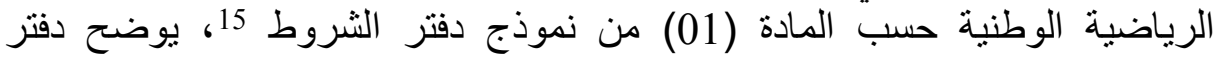
الثروط الالتز امات الواجب اكتتابها من قبل النادي الذي يطن دفح للإخول في الممارسة 


$$
\text { الرياضية الاحتر افية حيث يتعهد بما يلي: }
$$

- - الامتثال للقو انين الأساسية وتتظيمات الاتحادية أو الاتحاديات و الر ابطات

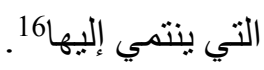

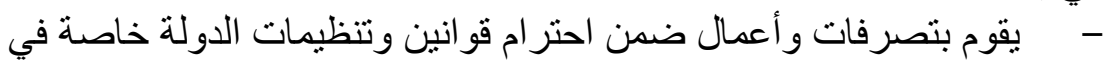

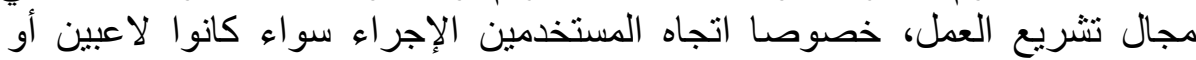
مؤطرين وطنيين أو أجانب.

- - احترام كل المقاييس والتعليمات في ميدان المصادقة وأمن المنشآت

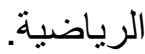

- - -

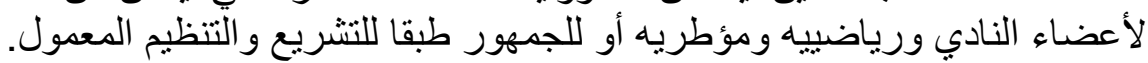

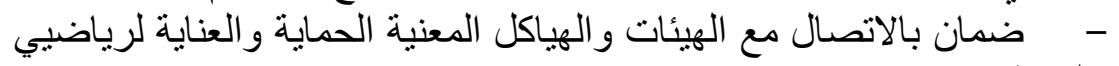

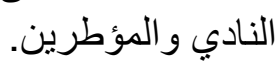

$$
\text { - - - الانضمام إلى الر ابطات والاتحاديات الرياضية. }
$$

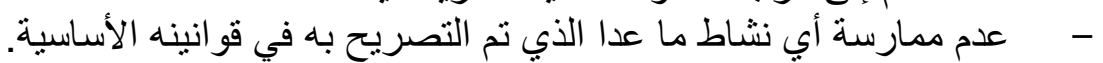

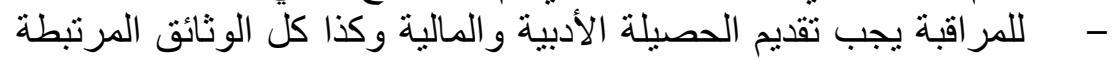
بسيره وتسييره بطلب من هيكل تسير الاتحادية وبطلب من الإدارة المكلفة بالرياضة الرية

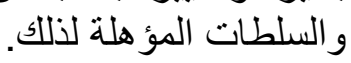

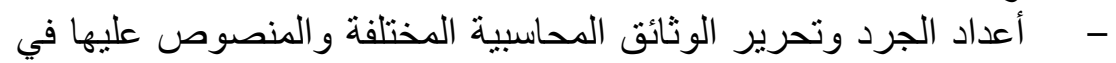

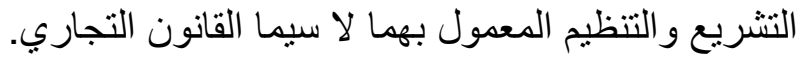

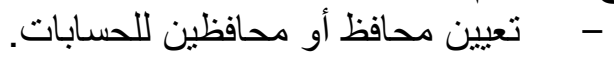

- - العمل على الوقاية من تعاطي المنشطات و العنف و مكافحتهما.

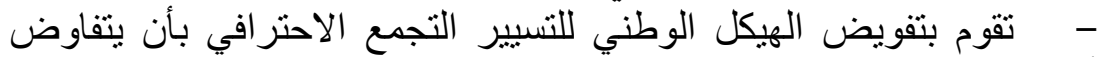

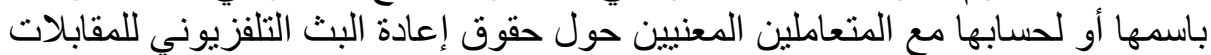

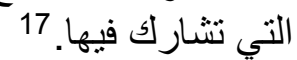

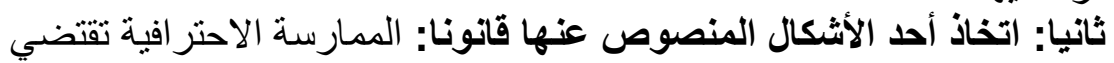

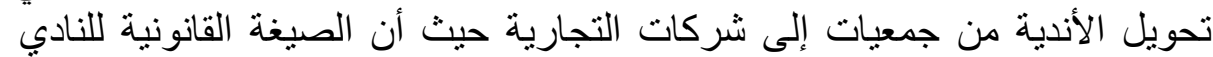

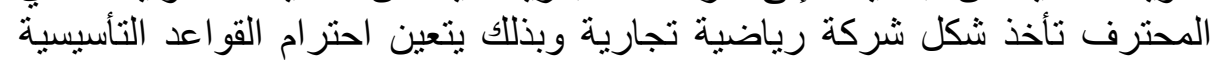

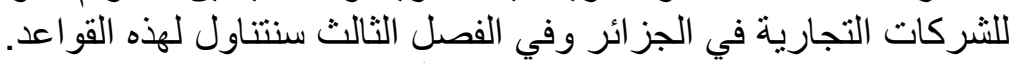
نص المشرع الجزائري على الأحكام العامة للشركات الترات التجارية في القانون

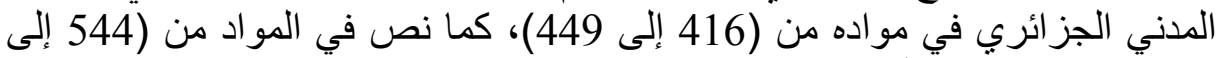

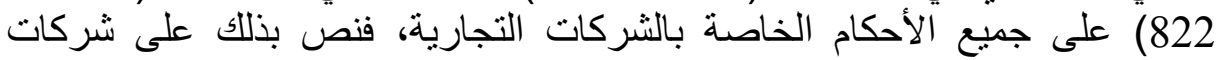

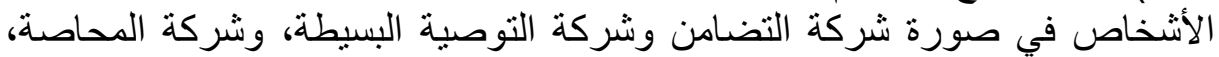

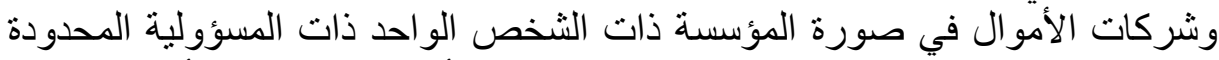

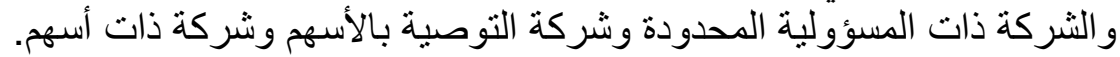

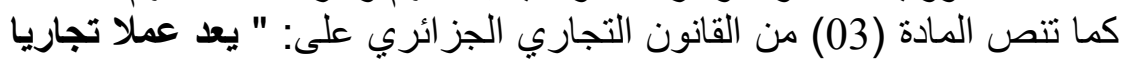

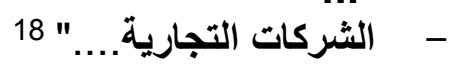

و عليه فإن المشروع التجاري التباري الذي يقوم ببعض الأعمال التي تعتبر أعمال

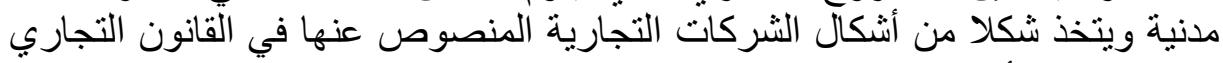

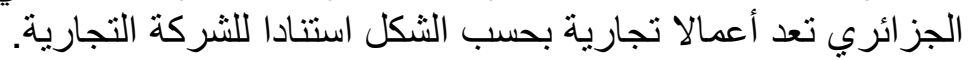

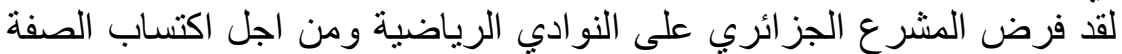

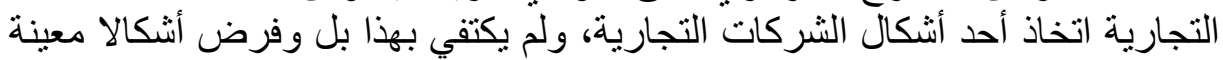

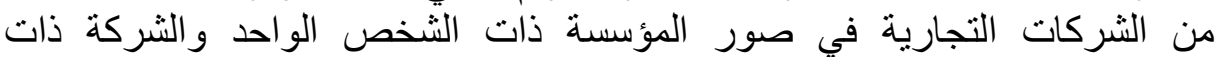
المسؤولية المحدودة وشركة ذات أسهم من أجل، حيث نصت ذات المادة (01 /03) من ذئ 


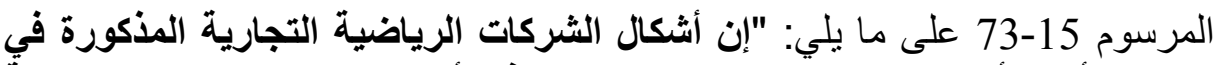

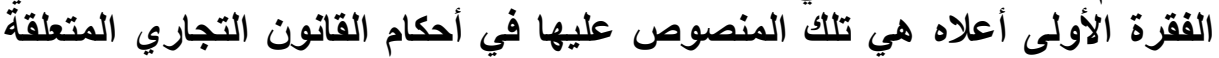

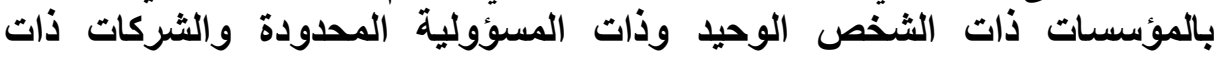
المسؤولية المحدودة، والثركات الثرات ذات الأسهر". 19

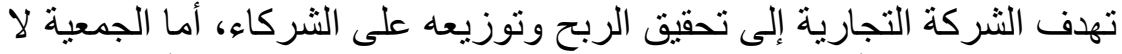

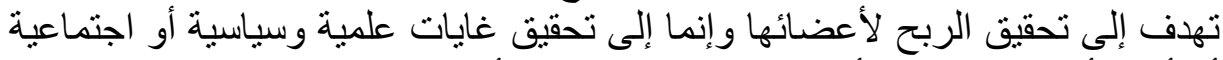

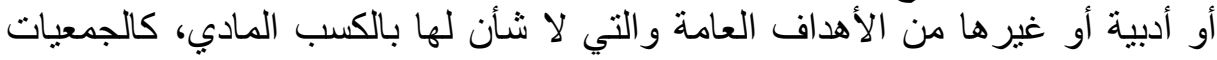

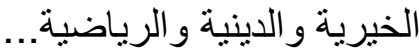

لقد فرض المشرع الجزائري على الثركة الرياضية التجارية اتخاذ أحد الترائ

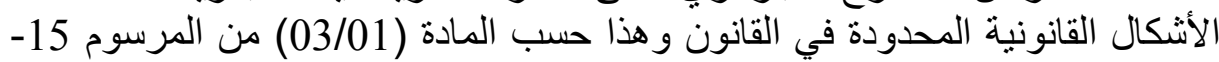

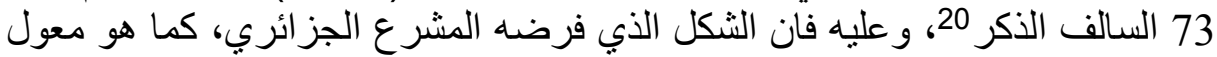

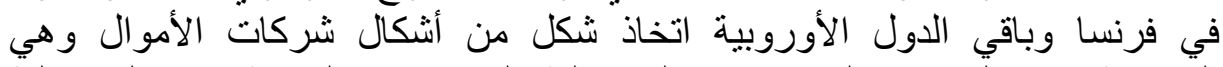

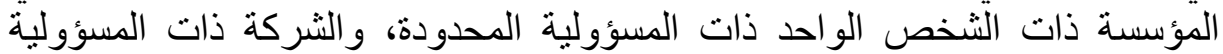

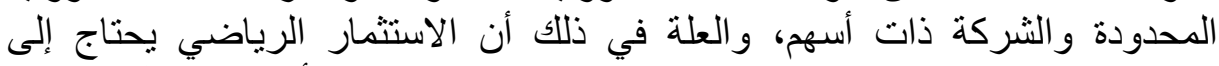

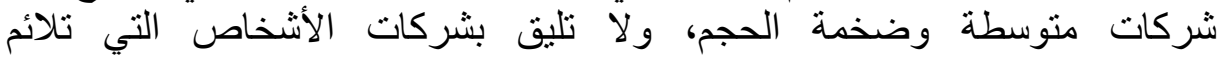

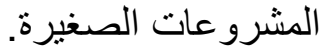

إن المشرع الجزائري حاول حصر الأشكال القانونية للشركة الرياضية

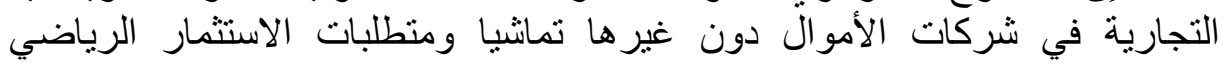
ثالثا: الموضوع الرياضي للشركة: أما من حيث موضوع الثركة الرياضية وتشعب نشاطاتها.

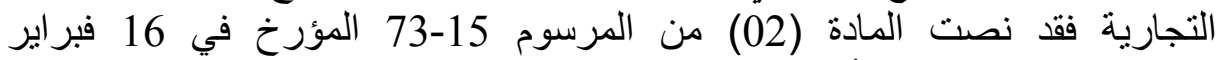

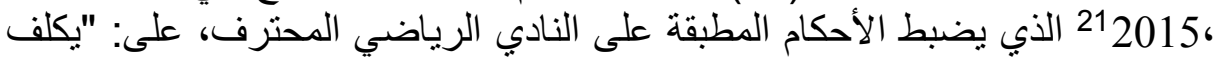

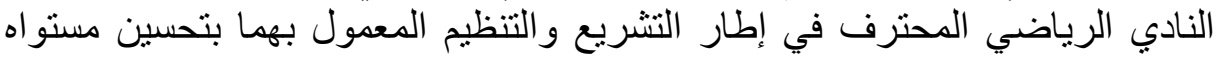

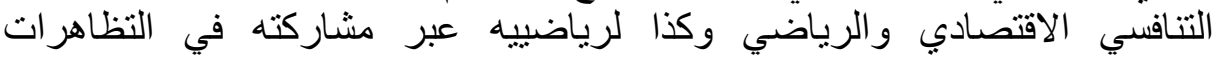

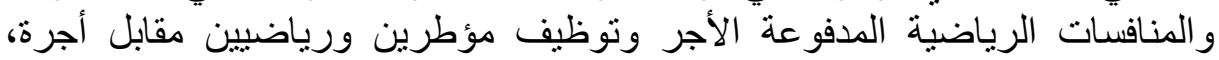

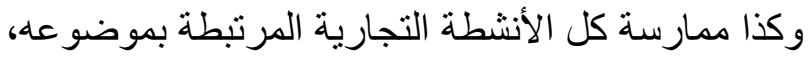
وبهذه الصفة يكلف بما يأتي: الأنية

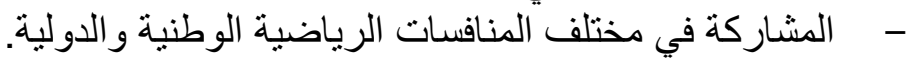

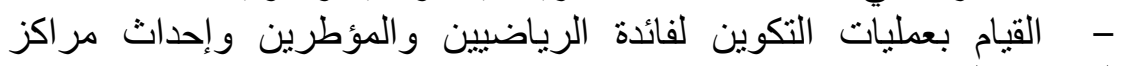
تكوين المواهب الرياضية. - - - منمان تدريب رياضيبي النادي وتأطير هم أو كل فريق آخر وتحضير هم - - المشاركة في انتقاء المو اهب الرياضية الثنابة وكثفها وتوجيهـا.

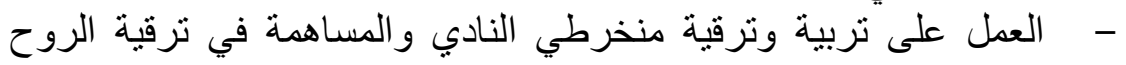
الرياضية. - - تنظيم التظاهر ات و العروض و المنافسات الرياضية المدفوعة الأجر.

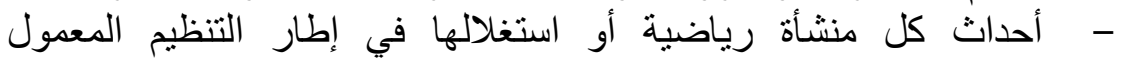
بهه،وتسيير وصيانة أملاك النادي. - - منح الرواتب لرياضيي النادي ومؤطريه ضمن احترام التشريع و التنظيم المعمول بهما. - - القيام بكل نشاط اشهار ورعاية وتكفل من شأنه المساهمة في تطوير 
- - - القيام بكل أنشطة تجارية واستثمار من شأنها تطوير موارده وضمان بقائه. - - ت تنظيم كل نشاط استر احة وترفيه لفائدة الثباب و الجمهور ".

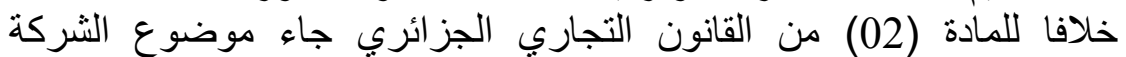

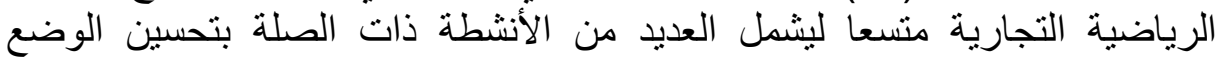

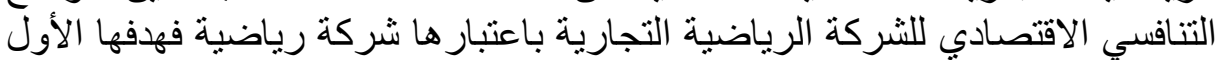

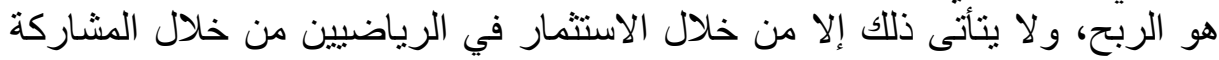

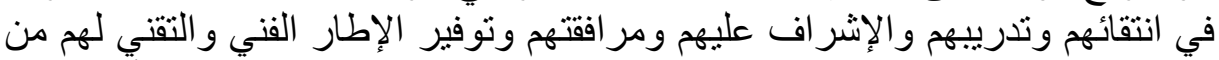

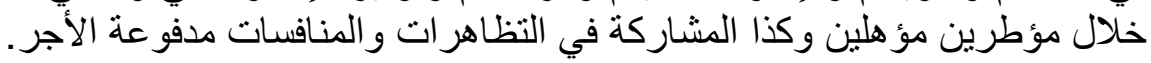

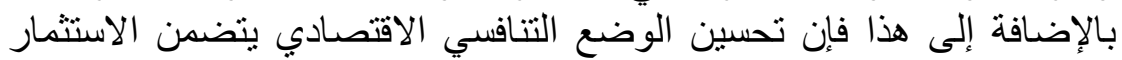

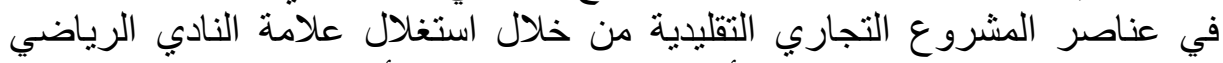

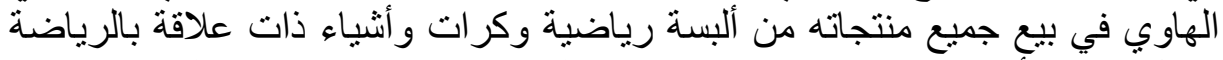

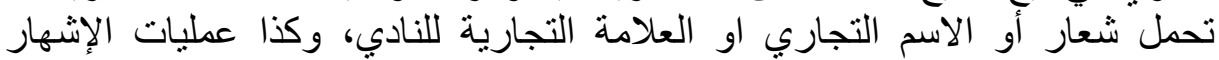

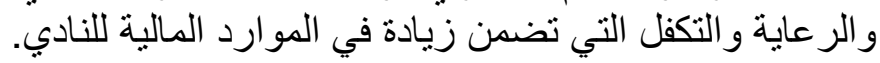

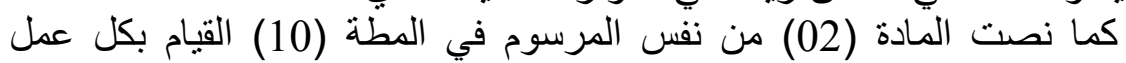

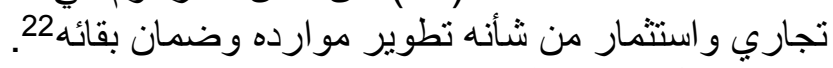

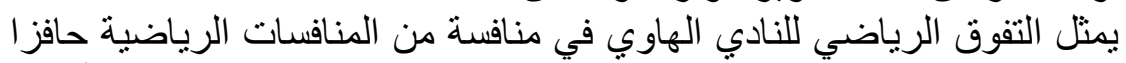

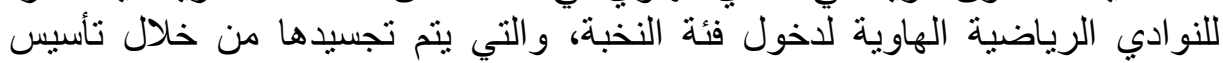

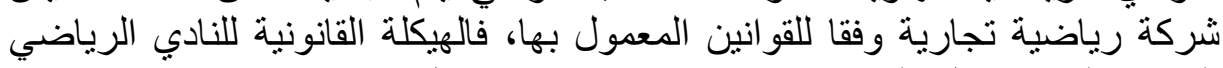

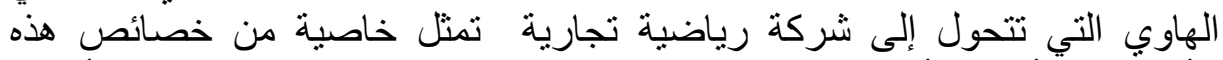

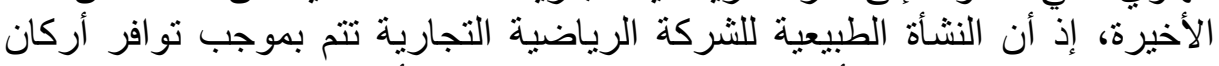

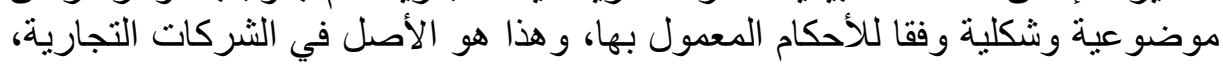

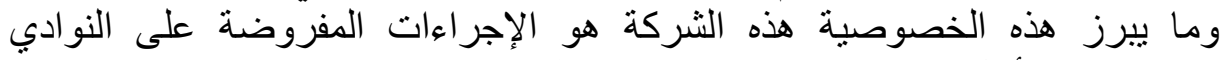

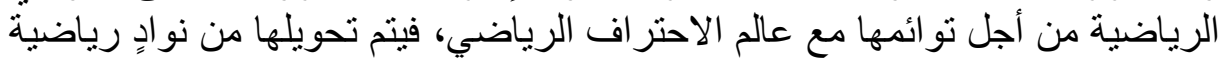

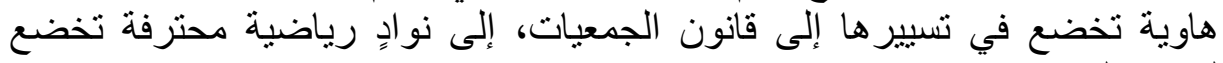

المطلب الثاني: دور النادي الهاوي في تأسيس الثركة الرياضية التجارية.

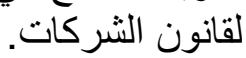

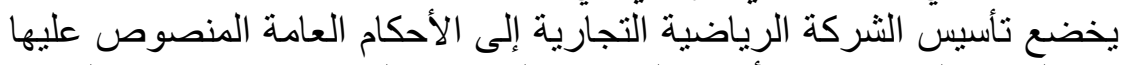

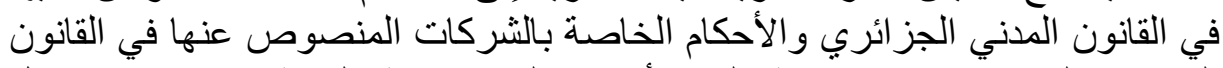

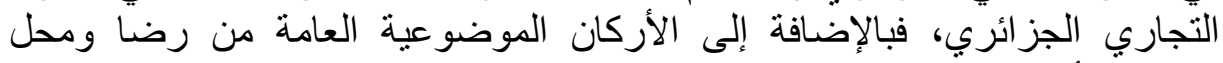

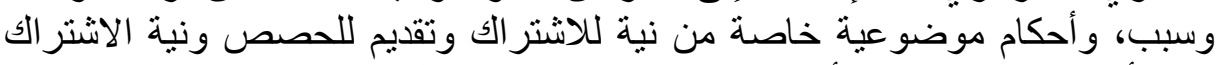

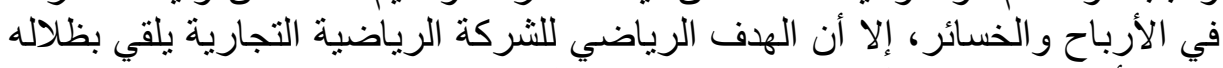

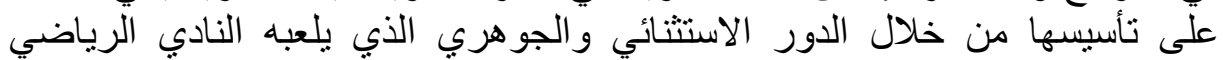

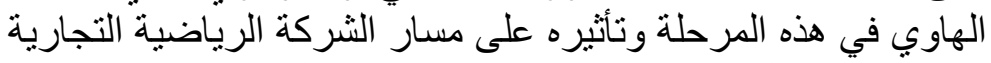

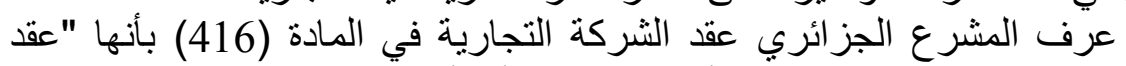

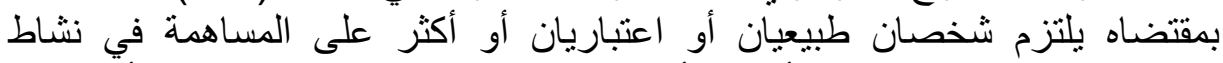

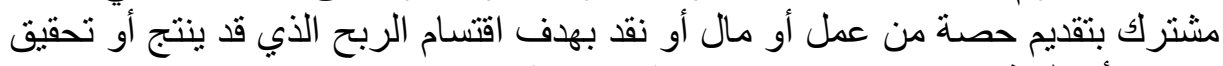

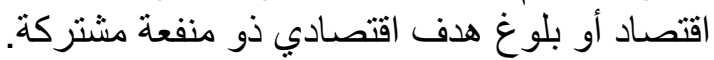

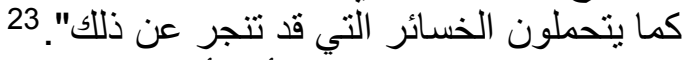

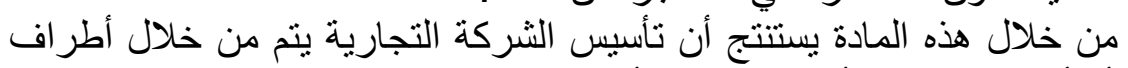

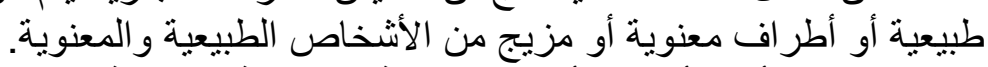

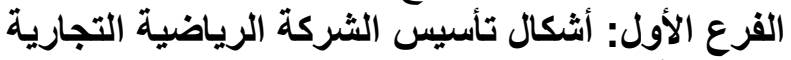

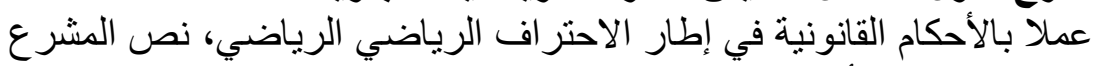

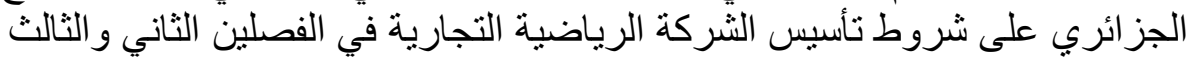


من المرسوم التنفيذي 15-73 الذي يضبط الأحكام المطبقة على النادي الرياضي

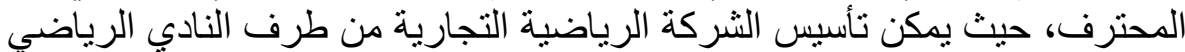

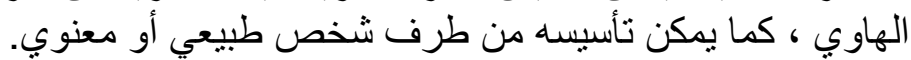

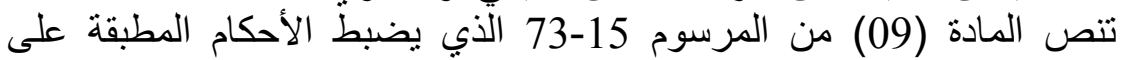

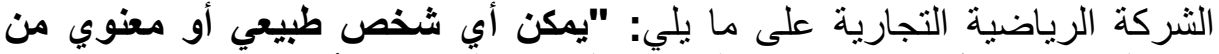

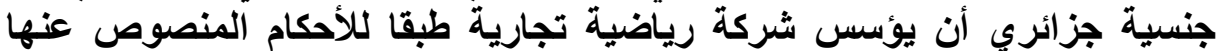
أدناه أولا: التأسيس من طرف النادي الرياضي الهاوي. تتص المادة (05) من المرسوم التنفيذي 15-73 الذي يضبطي النيط الأحكام المطبقة

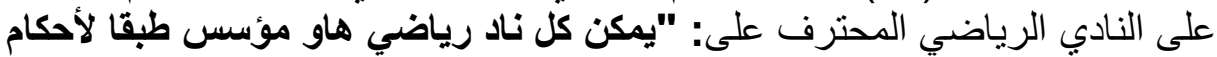

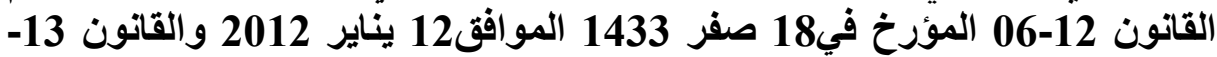
05 المؤرخ في 14 رمضان 1434 الموافق 23 يوليو 2013 والمونين فئكورين أعلاه،

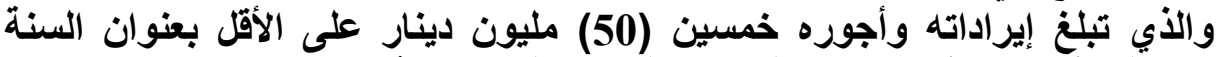

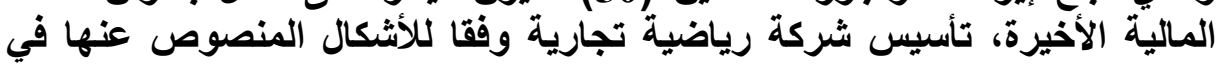

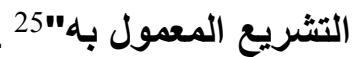

1- مفهوم النادي الرياضي: أصبح القطاع الرياضي من أهم مكونات الأني

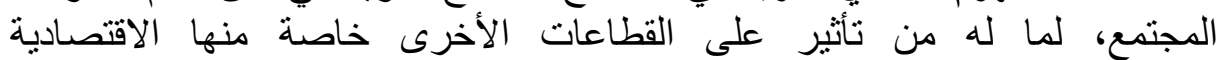

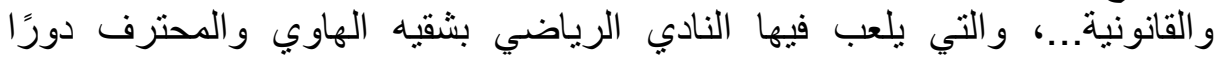

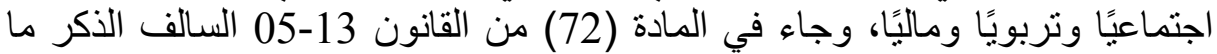

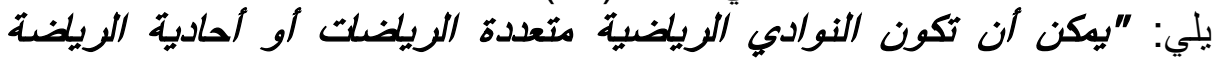
وتصنف إلى فتثنين:

\section{-

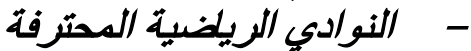

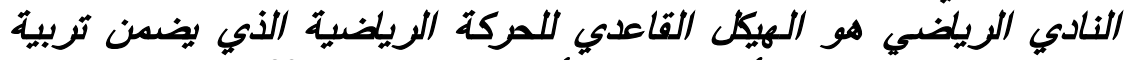

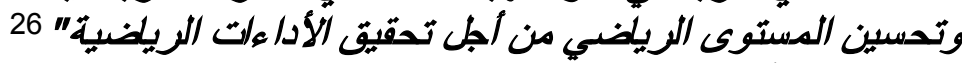

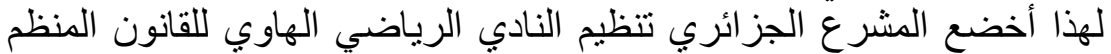

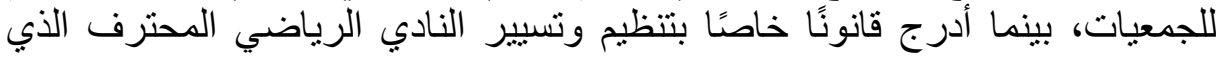

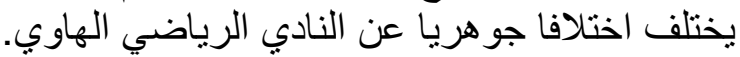

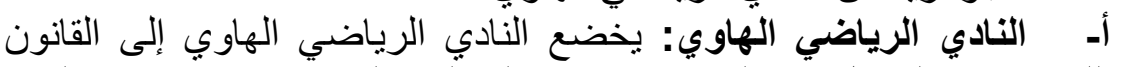

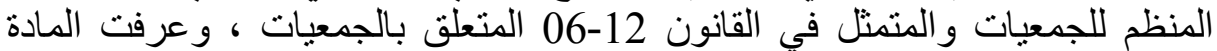

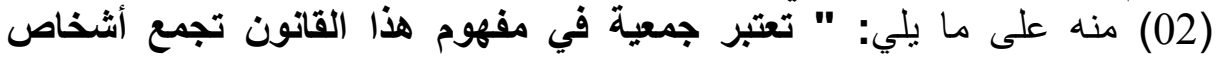

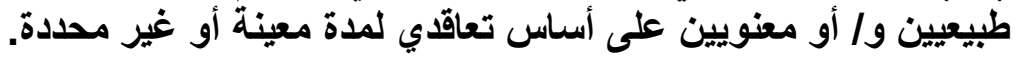

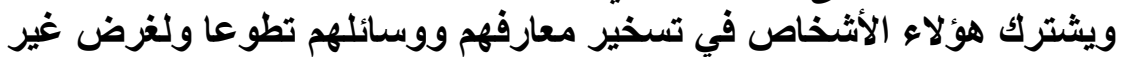

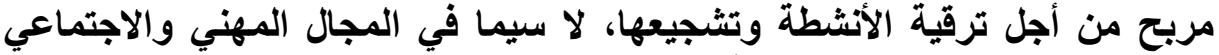

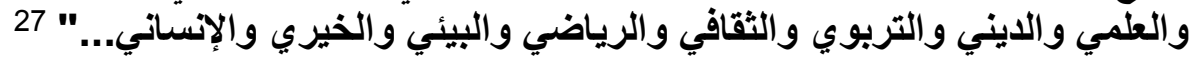

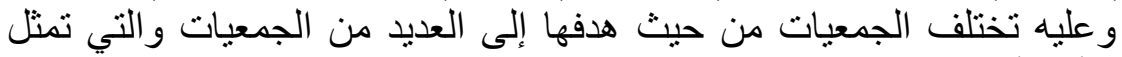

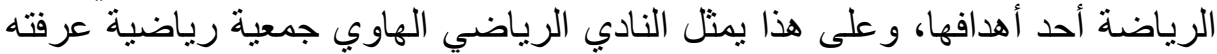

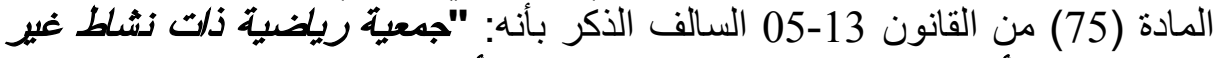

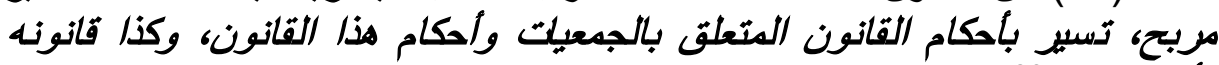

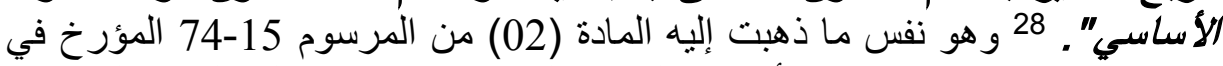
16 فبر اير 2015 الذي يحدد الأحكام و القانون النموذجي المطبق على المي النادي الرياضي

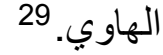
والجمعية الرياضية في الأصل مؤلفة من أثخاص تربطهم فكرة رياضية 
واجتماعية مجازة قانونيا في عملها بصفة دائمة ولها صفة قانونية لا تقصد الربح المادي، و إذ يجوز لها أن تكون محترفة فأنيا لأنشطة رياضية. 30

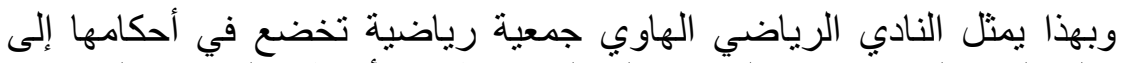

القانون المتعلق بالجمعيات، والقانون المتعلق بتنظيم الأنشطة البدنية والرية الرياضية

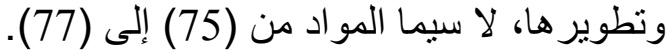

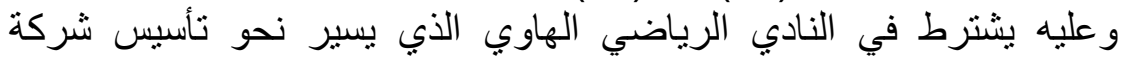

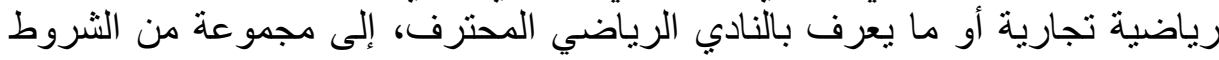

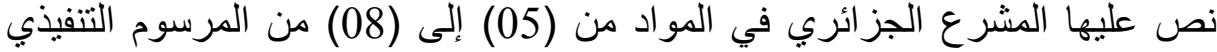

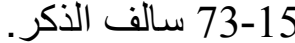

- - - أن ون تبلغ إيرادات وأجور النادي الرياضي الهاوي في السنة المالية الأخيرة خمسون مليون دينار جزائري (50.000.000 د ج) حسب النب المادة (05) من

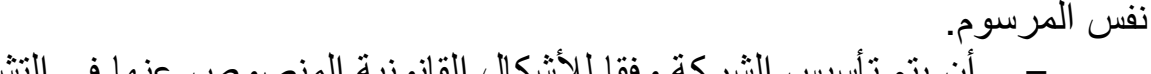
- - مأن يتم تأسيس الثركة وفقا للأشكال القانونية المنصوص عنها في النسريع الجزائري حسب المادة (05) من نفس المبن المرسوم.

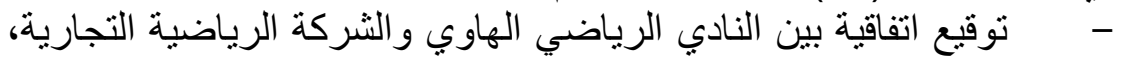

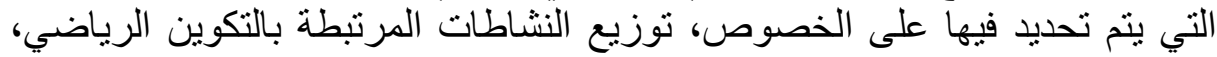

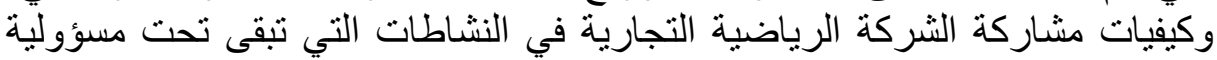

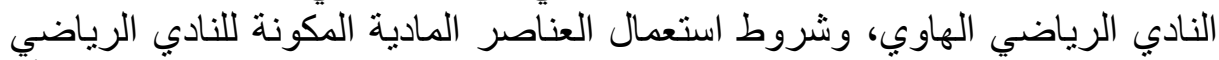

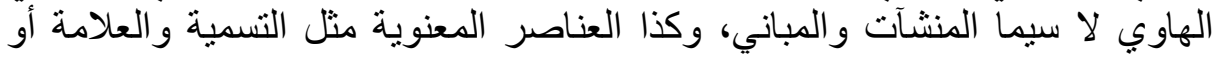

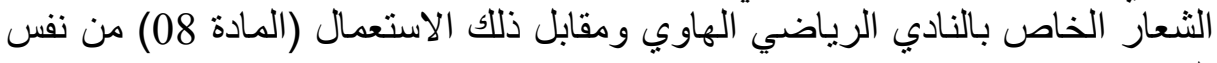

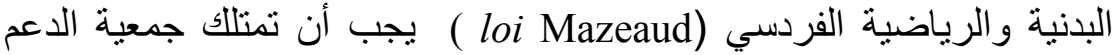
ثلث الثركة التجارية التي تم إنشاؤها، 31

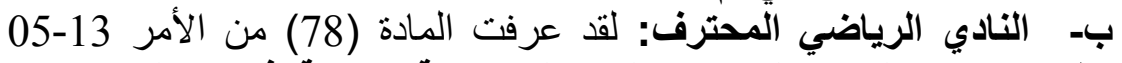

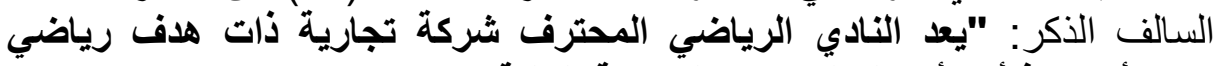
يمكن أن يتخذ أحد أشكال الشركات التجارية التربية التالية:

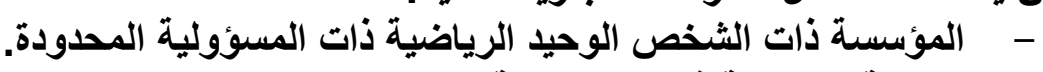

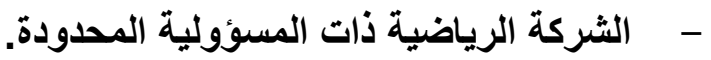

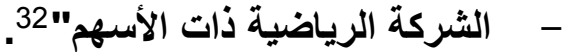

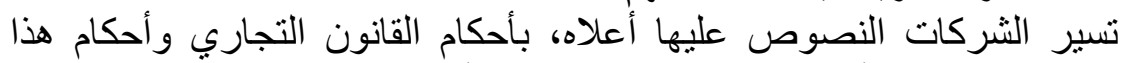

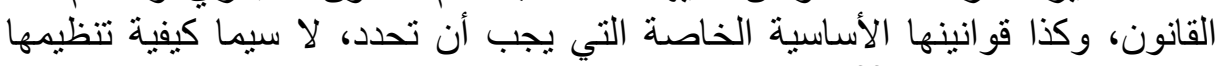

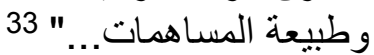

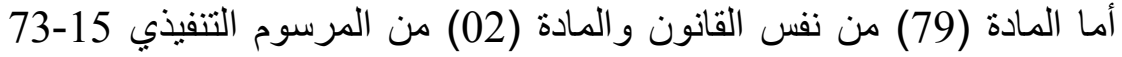

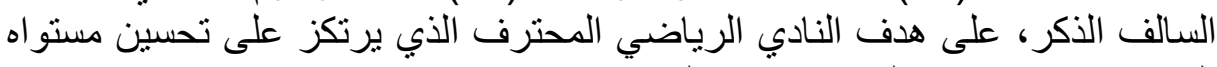

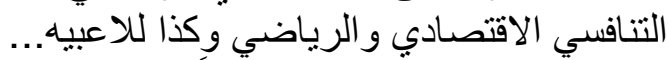

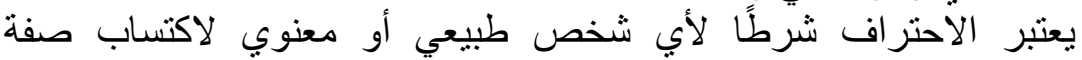

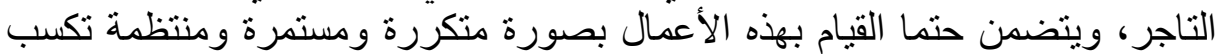
الشخص صفة التاجر .

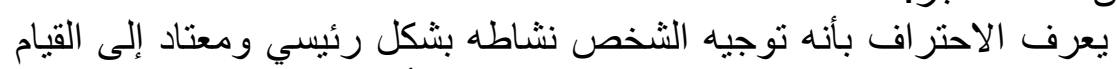

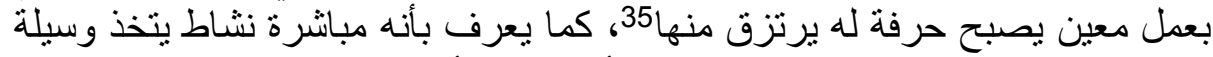

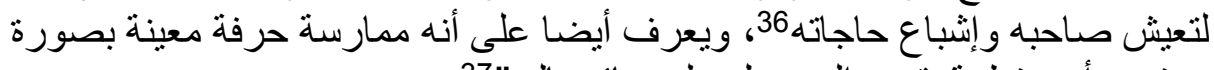

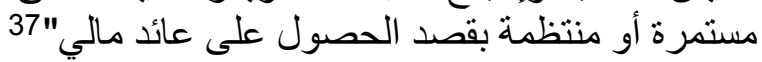
إن الاحتر اف الرياضي هو نوع من أنواع الاحتر اف، إذ أن كل احتر اف ينصب 
على عمل ما سواء كان ذلك في مجال الصناعة أو التجارة أو الزراعة أو الرياضية،

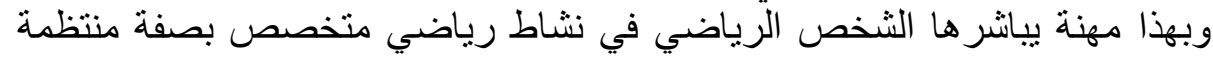

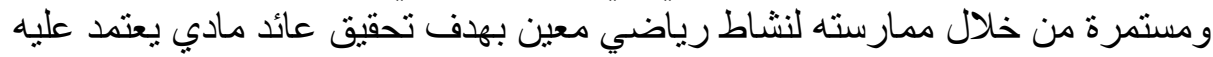

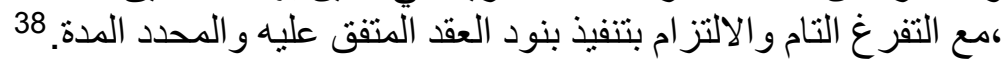

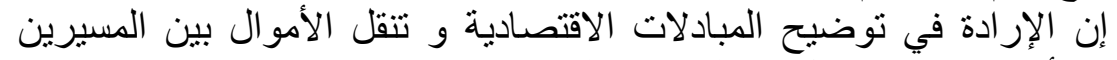

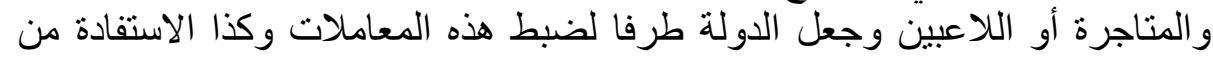

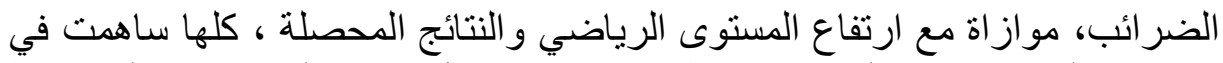

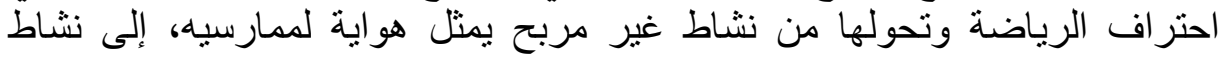

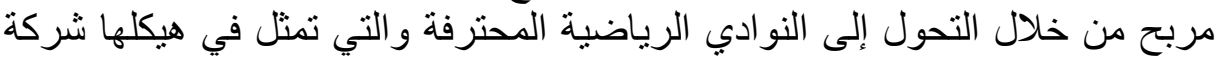

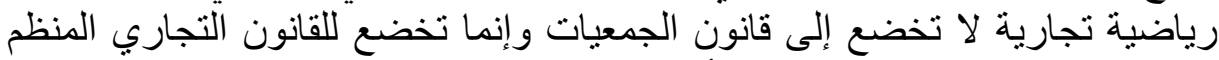

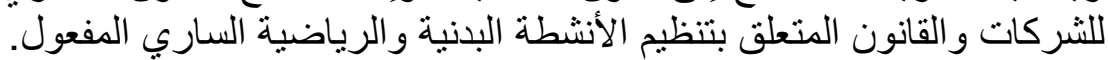

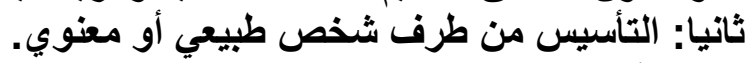

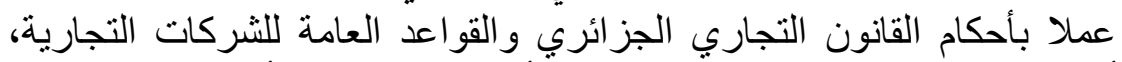

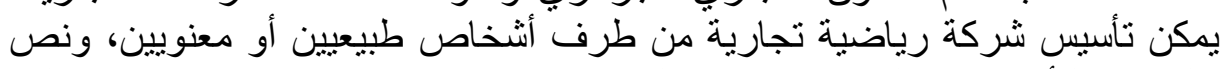

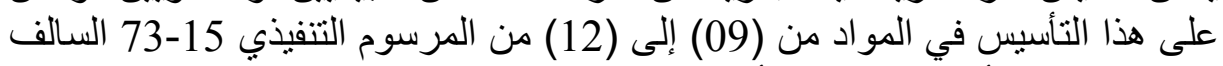

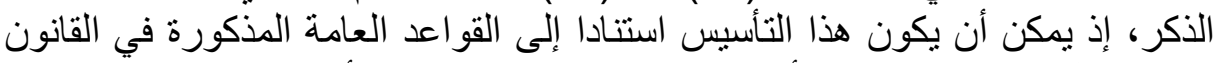

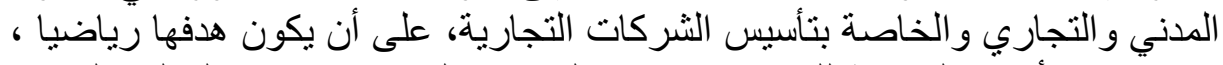

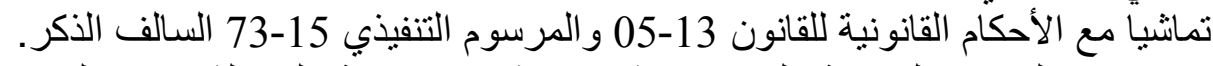

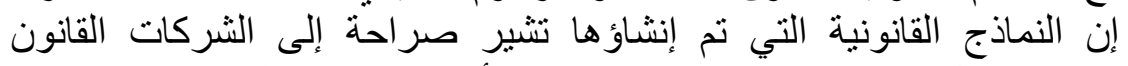

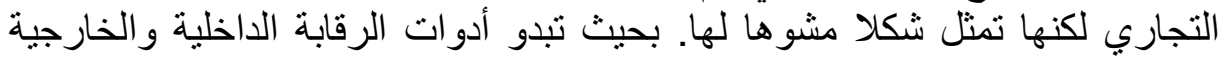

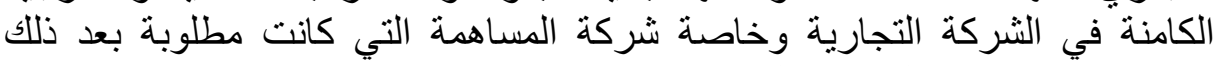

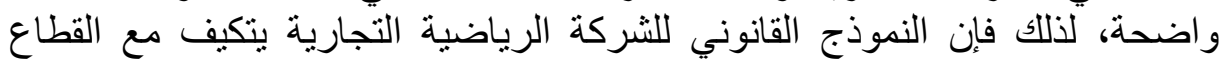

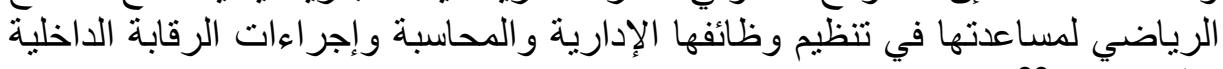
و الخارجية. 39

الفرع الثاني: انسحاب مقومات النادي الرياضي الهاوي إلى الثركة الرياضية

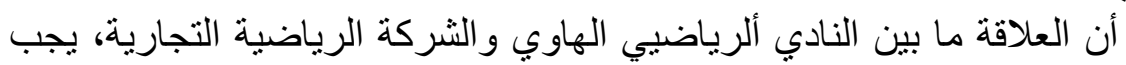

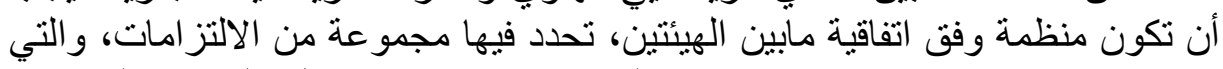

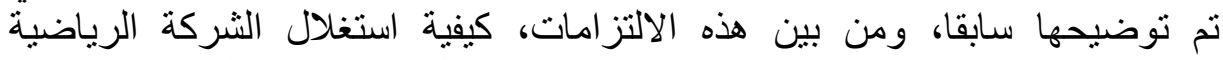

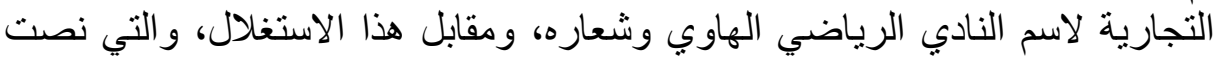

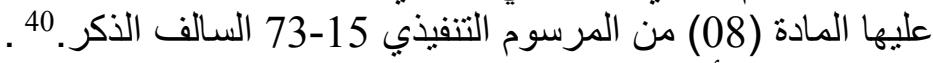

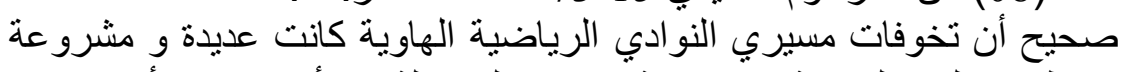

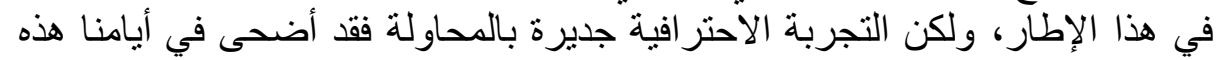

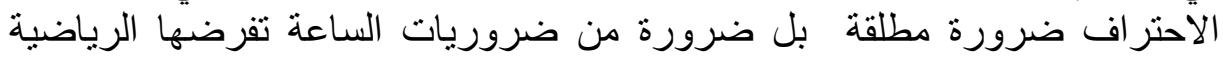

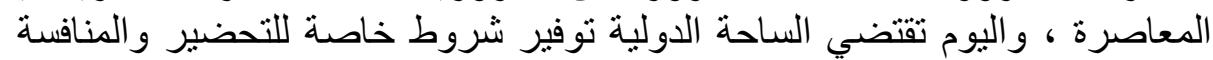

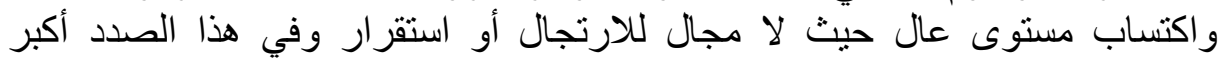

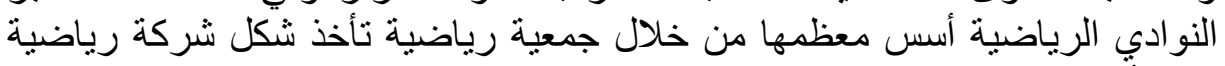

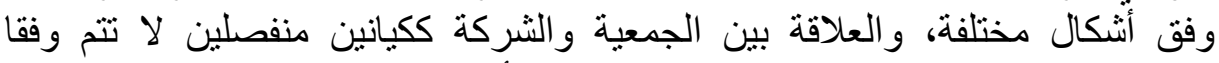

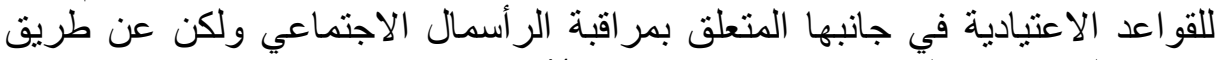
اتفاقية ملزمة تمنح الجمعية صلاعلاحيات محددة.

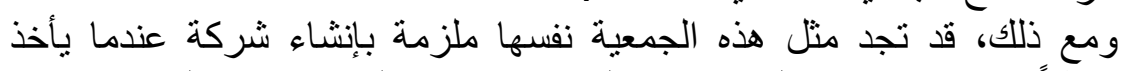

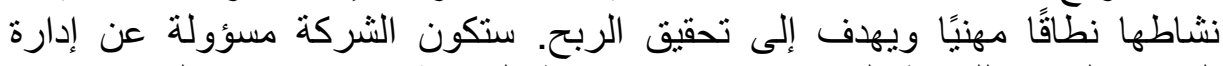

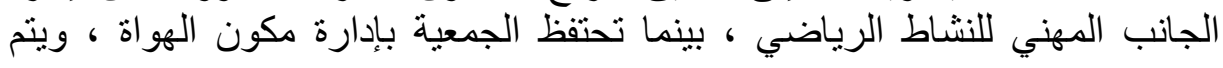


تحديد المعايير بوضوح 42

تقوم الثركة الرياضية التجارية في أغلب الأحوال على الجمعيات الرياضية

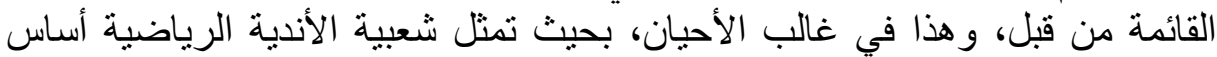

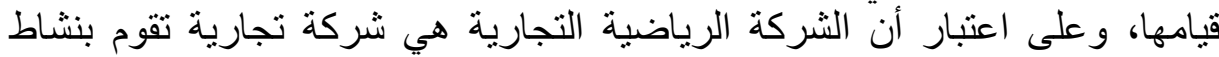

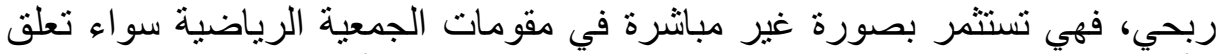

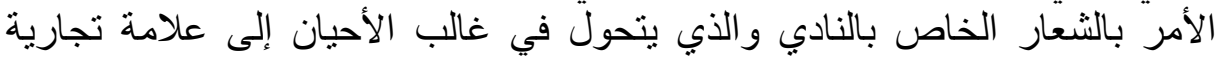

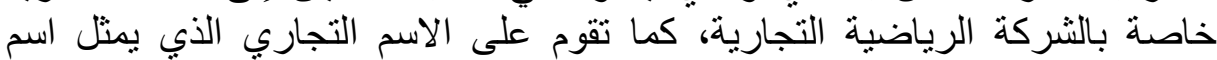

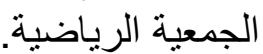

تحديد النشاطات وفق اتفاقية مبرمة بين النادي الهاوي والثركة الرياضية

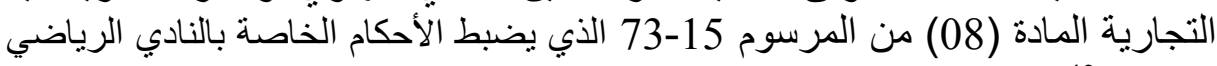

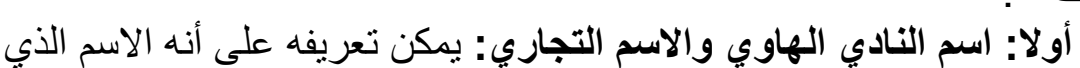

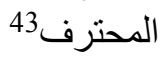

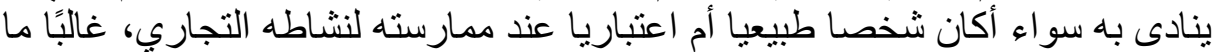

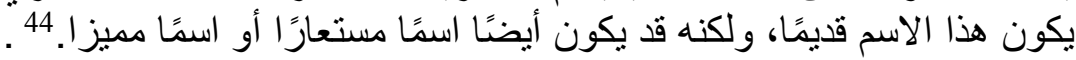

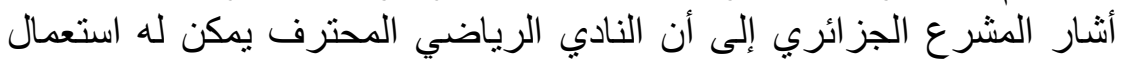

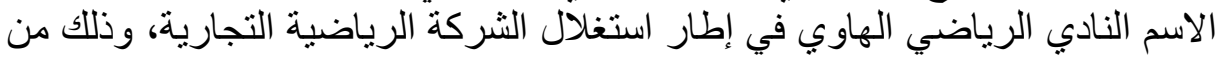

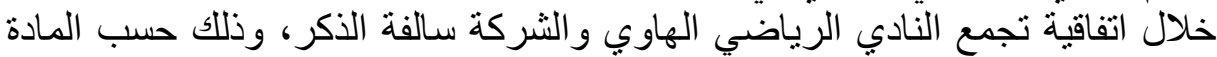

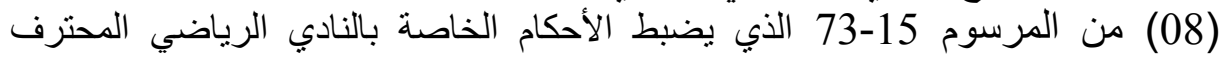

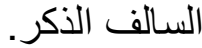

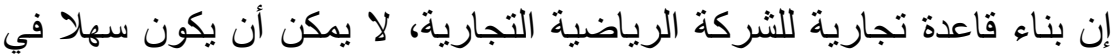

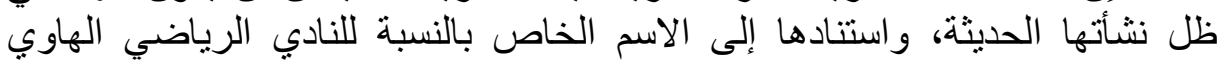

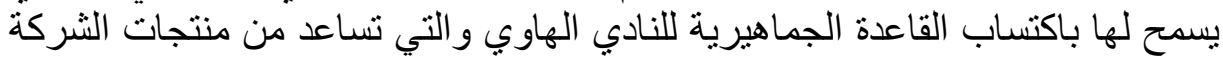

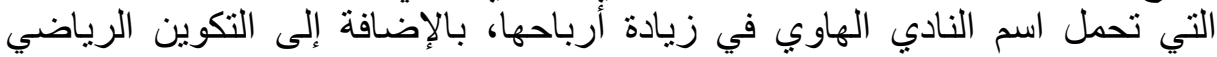
و السمعة التي يتمتع بهاً النادي النهاوي.

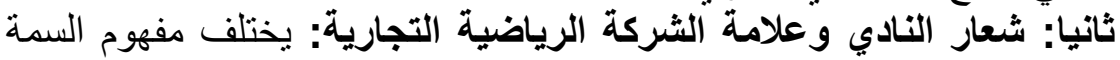

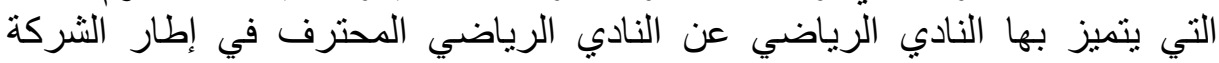

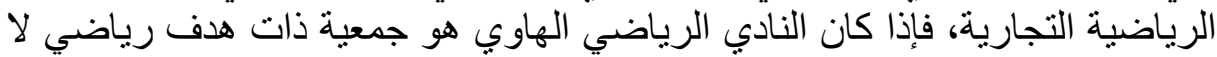

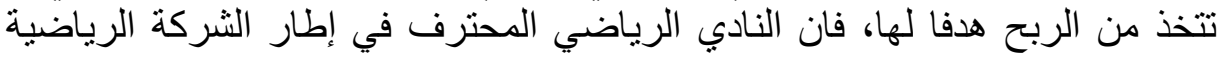

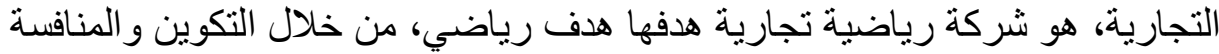

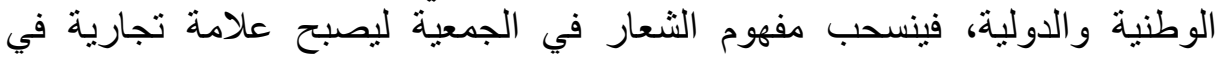
الثركة الرياضية التجارية، تمثل بهذا المعنى عنصر الية ماليا مكونا للأمة المالية للشركة الرياضية التجارية.

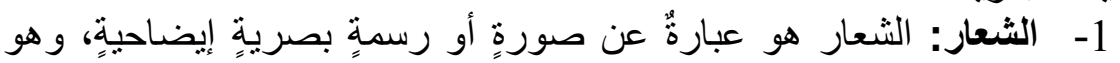

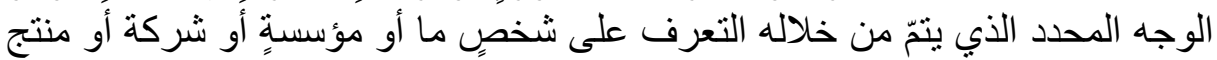

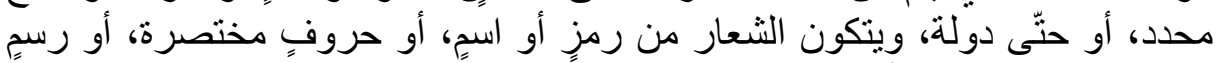

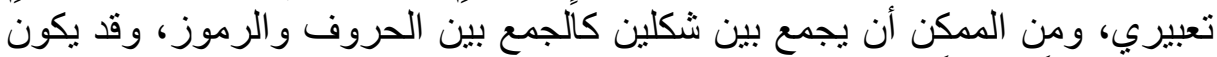

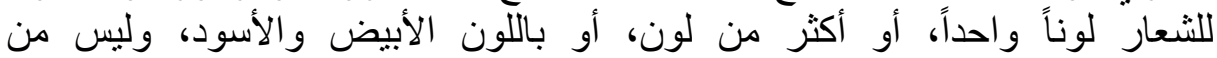

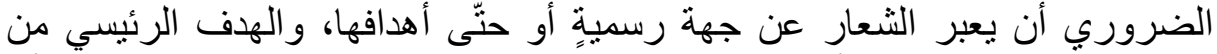

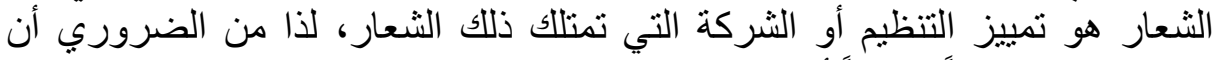

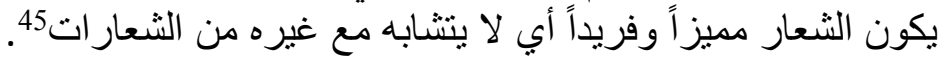

الشعار هو سمة أو علامة خارجية، أو نقش مثبت على مبنى منى مرتبط بالنشاط

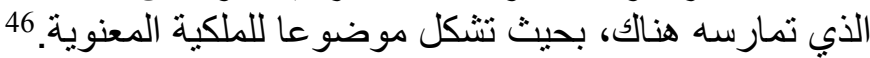

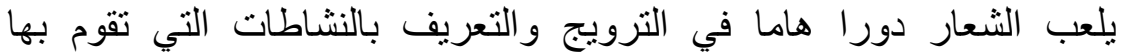

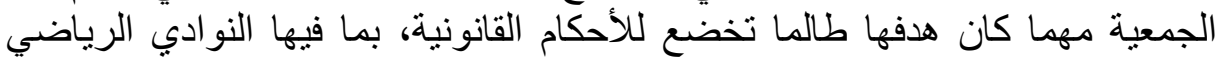




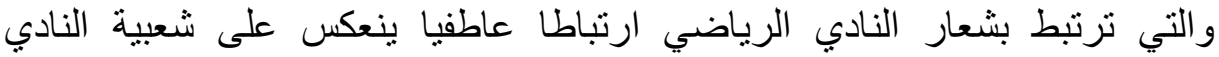

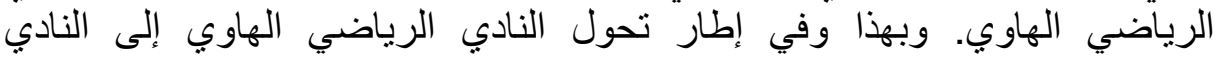

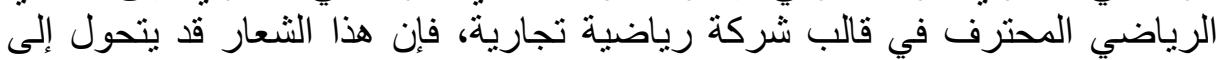

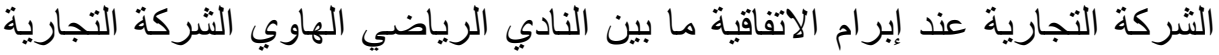

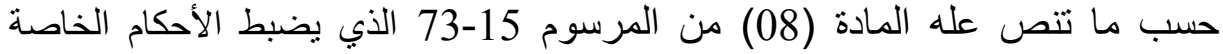

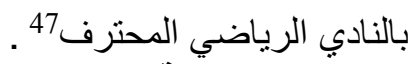

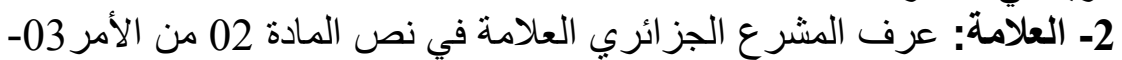

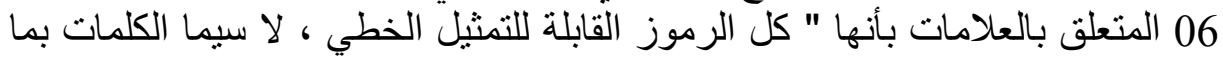

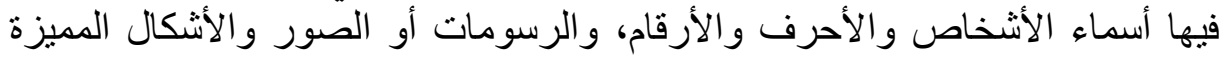

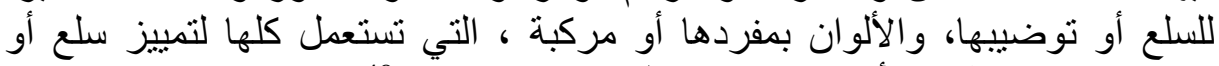

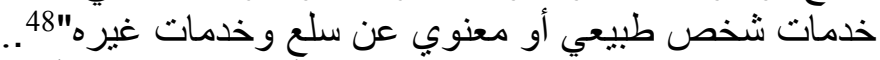

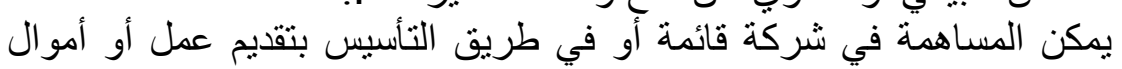

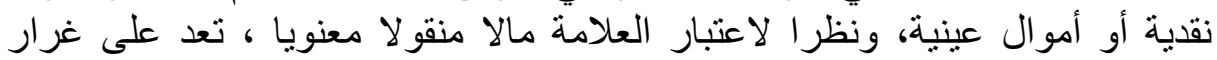

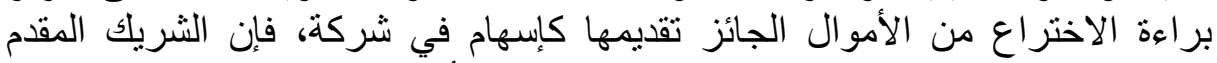

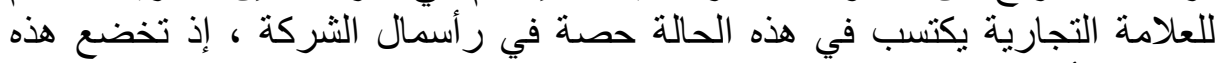

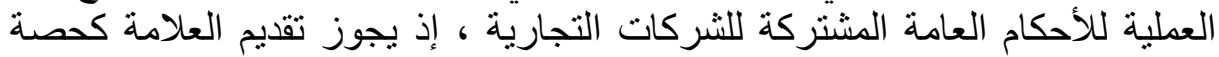

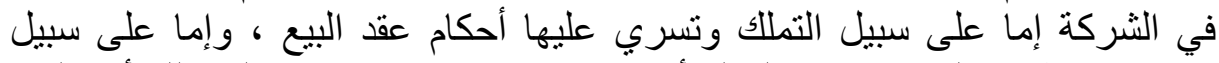

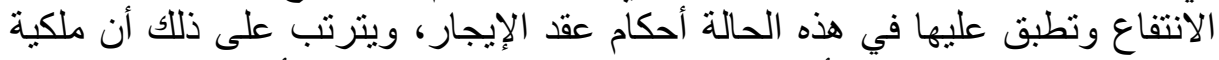

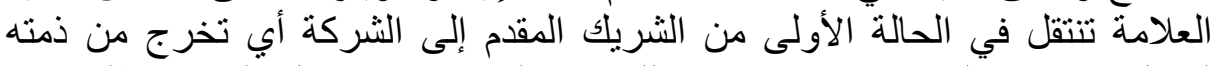

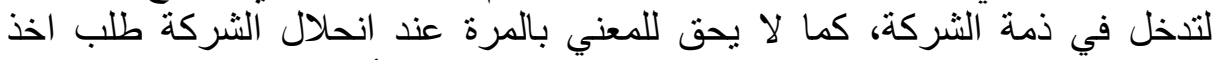

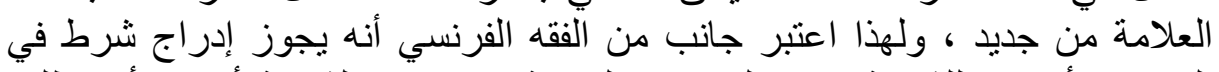

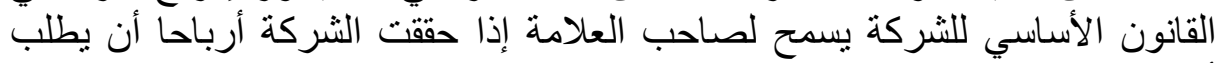

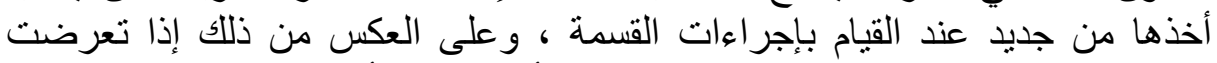

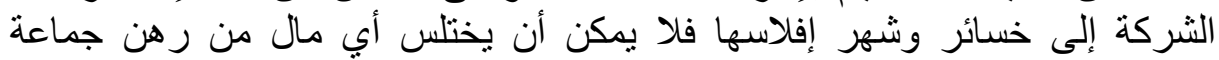

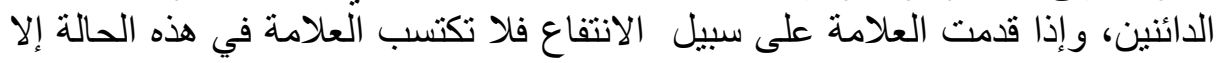

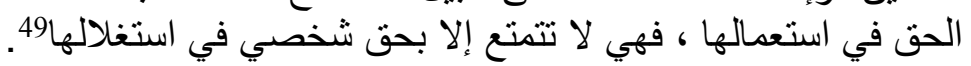

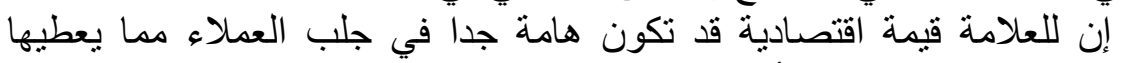

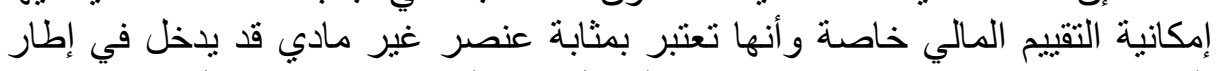

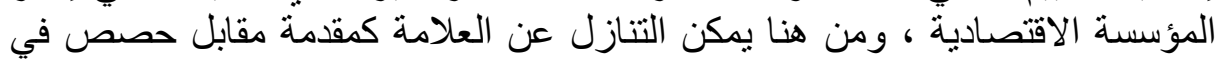

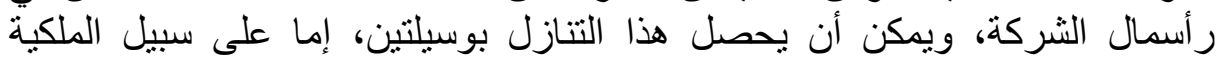

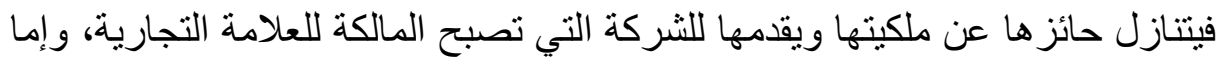

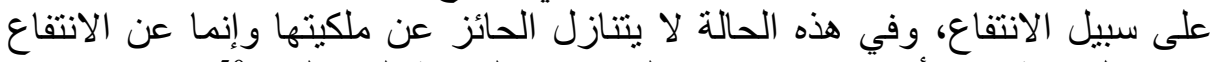

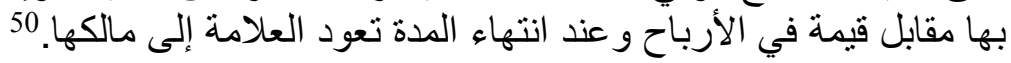

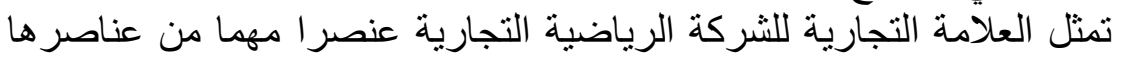

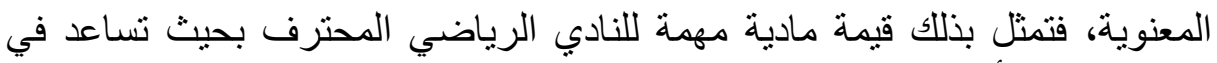
شهرته وزيادة أرباحه المعتمدة على نجاحه الرياضي وادي التسويقي.

IV

ألقى التطور التشريع في المجال الرياضي أثرا بارزا على الهيكلة القانونية للنوادي

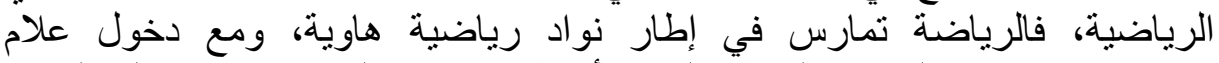

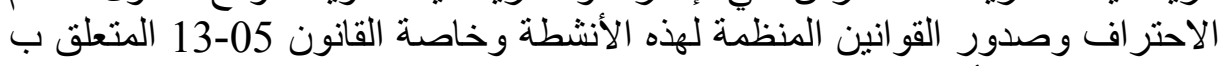

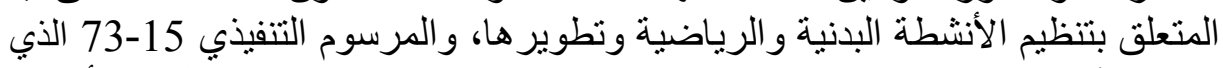

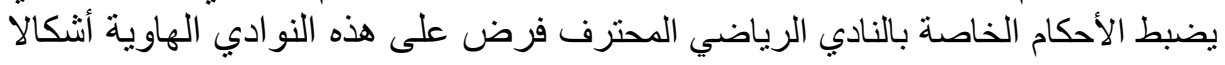




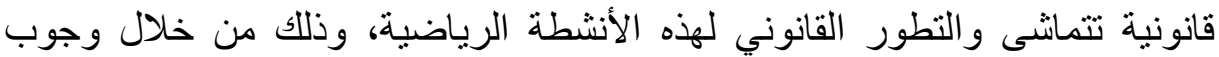

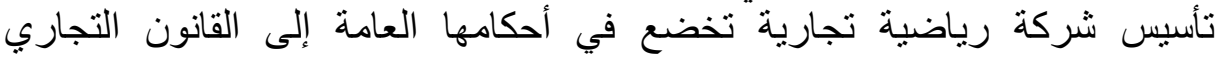

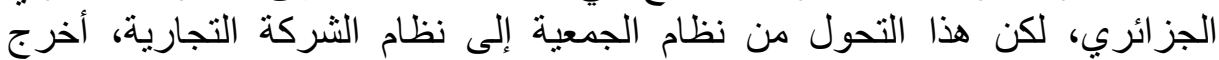

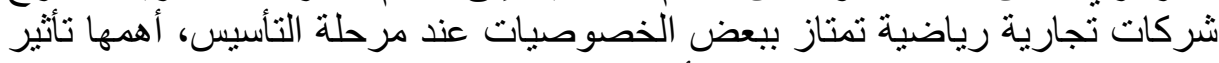

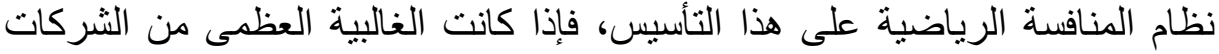

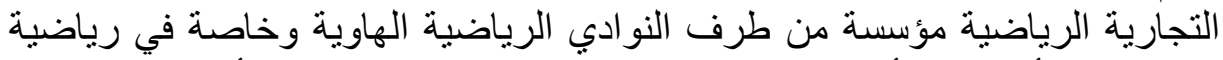

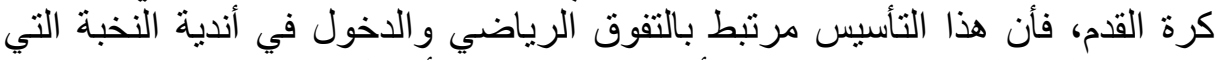

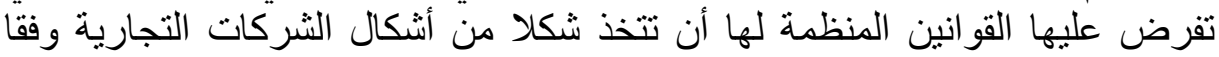

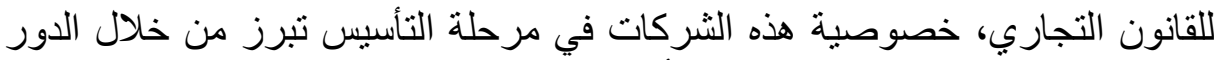

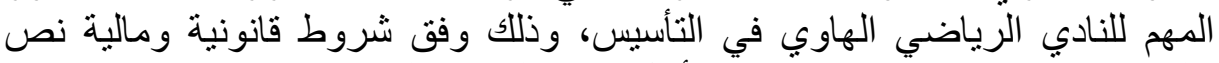

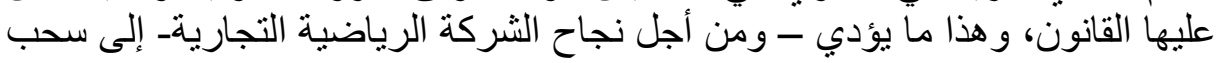

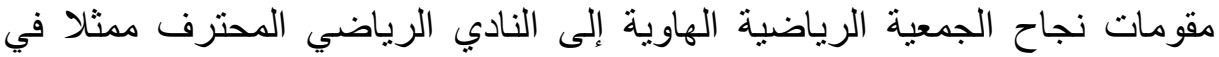
الثركة الرياضية التجارية.

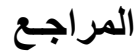

1ـ أنظر الجريدة الرسمية العدد:39 لسنة 2013، الصادرة بتاريخ 31 يوليو 2013.

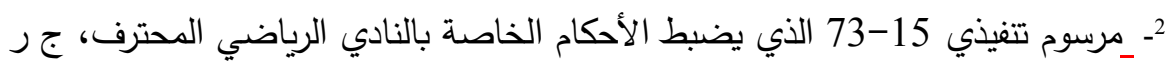

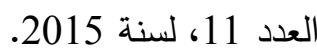

3ـ أنظر الجريدة الرسمية العدد:39 لسنة 2013، الصادرة بتاريخ 31 يوليو 2013. 4- أنظر الجريدة الرسمية العدد:11 لسنة 2015، الصادرة بتاريخ 25 فيفري 2015 التردية 5- أمر 75-58 المؤرخ في26 سبتمبر 1975 المتضمن القانون المدني الجزائري، المعدل

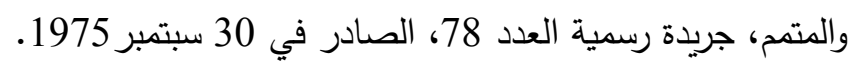

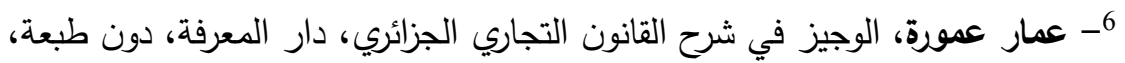

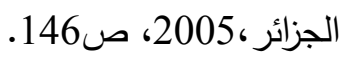
7- أمر 75-59 المؤرخ في26 سبتمبر 1975 المتضمن القانون التجاري الجزائري، المعدل

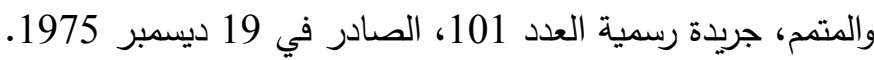

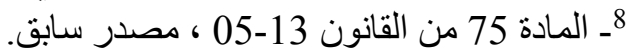

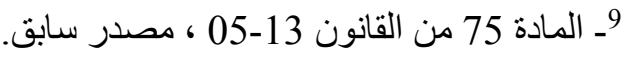

10ـ أمر 75-59 المؤرخ في 26 سبتمبر 1975 المتضمن القانون التجاري الجزائري، مصدر ، مدر سابق. 11- مشروع دفتر الثروط المقترح من طرف وزارة الثباب والرياضة مع الاتحادية الوطنية لكرة

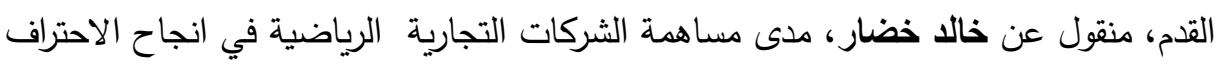
في كرةالقدم الجزائري، دراسة ميدانية على أندية كرة القدم للرابطتين المحترفتين الاولى والثانية. مذكرة مهاية التخرج ضمن متطلبات نيل شهادة الماجيستير في نظرية ونهجية التربية البدنية والرياضية، معهد التربية البدنية والرياضية، جامعة الجزائر 03،

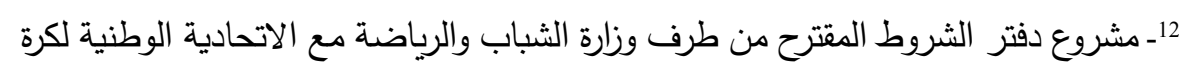

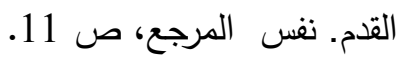


13-_ مرسوم تتفيذي 15-73 الذي يضبط الأحكام الخاصة بالنادي الرياضي المحترف، جر

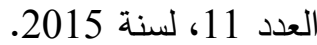

14-_ أنظر الجريدة الرسمية العدد:44 لسنة 2010، الصادرة بتاريخ 01 يوليو 2010.

15_ـ_أنظر الجريدة الرسمية العدد:44 لسنة 2010، الصادرة بتاريخ 01 يوليو 2010.

16 - Fronçois SALIANI, l'habilitation des personnes privees à gérer un service public , 1997, p5

17 ــ مشروع دفتر الشروط المقترح من طرف وزارة الشباب والرياضة مع الاتحادية الوطنية لكرة

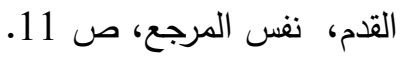

18- الأمر 75-59 المؤرخ في 26 سبتمبر 1975 المتضمن القانون التجاري الجزائري المعدل

والمتمم، الجريدة الرسمية 101 لسنة 1975.

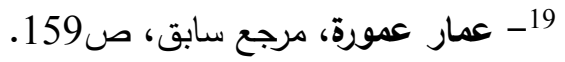

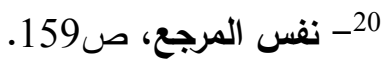

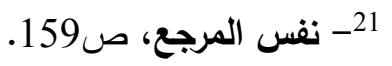

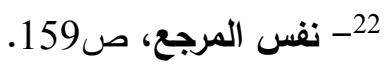

23ـ أمر 75-58 المؤرخ في26 سبتمبر 1975 المتضمن القانون المدني الجزائري، المعدل

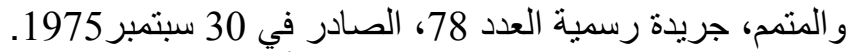

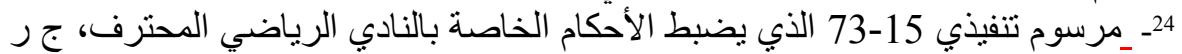

العدد 11، لسنة 2015.

25_ــرسوم تنفيذي 15-73 الذي يضبط الأحكام الخاصة بالنادي الرياضي المحترف، ج ر

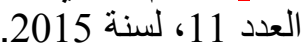

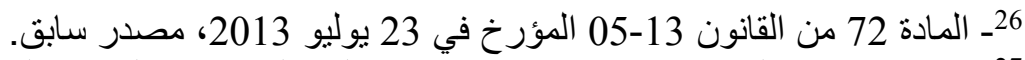

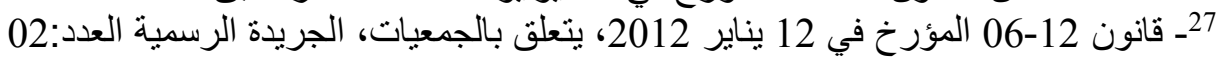

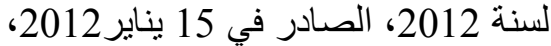

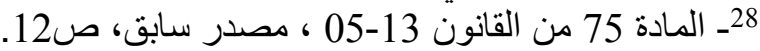

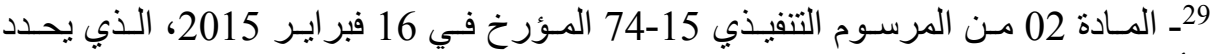

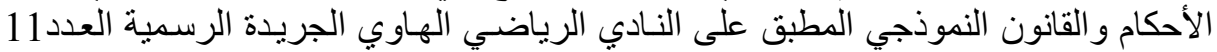

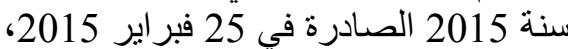

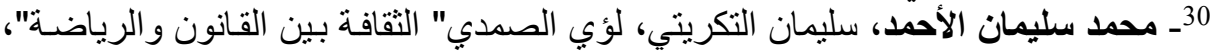

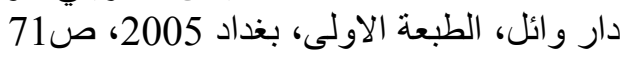

31 -Nadine DERMIT-RICHARD. L'évolution juridique des clubs de football : de l'association à la société commerciale RIMHE : Revue Interdisciplinaire Management, Homme \& Entreprise2013/2 n 6 | pages 36 à 51 .https://www.cairn.info/revue-rimhe-2013-2-page-36.htm.

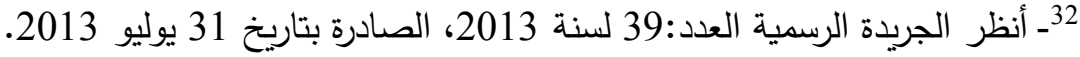

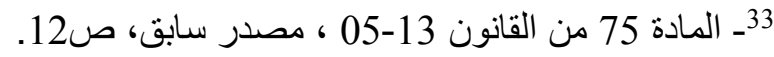

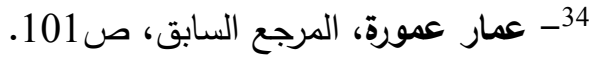


35- محمد سليمان الأحمد، الوجيز في العقود الرياضية، دار النهضة العربية، القاهرة، مصر،

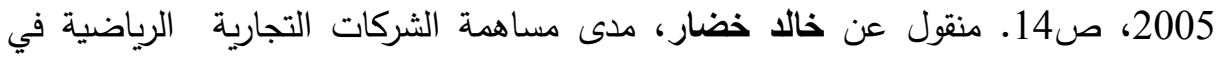

انجاح الاحتراف في كرةالقدم الجزائري، دراسة ميدانية على أندية كرة القدم للرابطتين المحترفتين

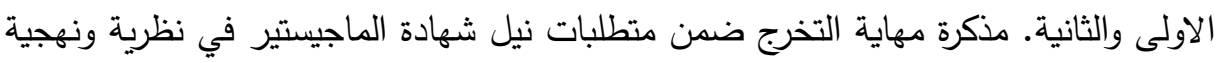

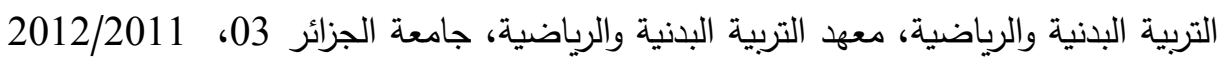

36 -G. Ripert et Rablot , Traité élémentaire de droit Commercial,

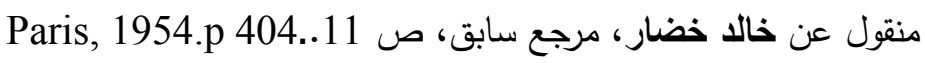

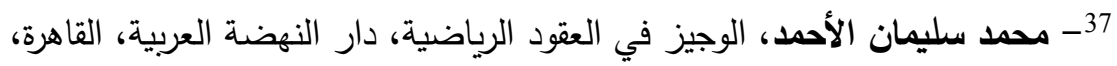

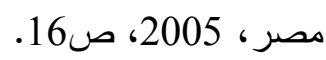

38- كمال درويش و السعيد خليل السعداني، الوجيز في العقود الرياضية، دار النهضة

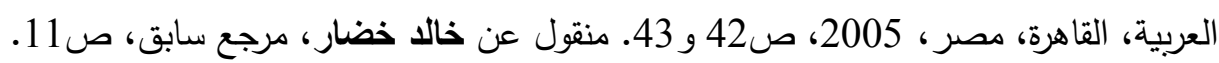

39 -Nadine DERMIT-RICHARD. L'évolution juridique des clubs de football : de l'association à la société commerciale RIMHE : Revue Interdisciplinaire Management, Homme \& Entreprise2013/2 $\mathrm{n}^{\circ} 6$ | pages 36 à 51 .https://www.cairn.info/revue-rimhe-2013-2-page-36.htm

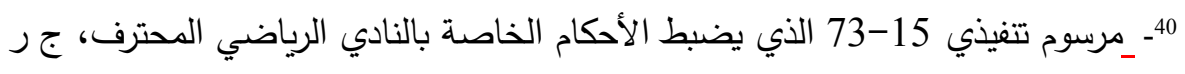

العدد 11، لسنة 2015.

41 - Jean-Pierre DENIS et Jean-François LAMOUR " certains aspects du sport professionnel en France, novembre 2003.

42 - https://www.alexia.fr/fiche/6635/structure-sportive.htm.

$$
\text { 43-_مرسوم تتفيذي 15-73 الذي يضبط الأحكام الخاصة بالنادي الرياضي المحترف، جر }
$$

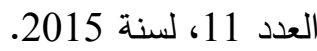

44 Annie CHAMOULAUD-TRAPIERS ,Droit des affaire, édition briel, paris 2001.p104.:

Il peut être défini comme l'appellation sous laquelle le commerçant, personne physique ou morale exerce son activité. Très souvent, c'est un nom patronymique, mais ce peut être également un pseudonyme ou une d'nomination de fantaisie.

45 - https://99designs.com/blog/tips/what-is-a-logo/

Annie CHAMOULAUD-TRAPIERS, Op.cit. .p105.

L'enseigne, c'est un signe extérieur, une inscription apposée sur un immeuble est se rapportant à l'activité qui s'y exerce. L'enseigne, constitue l'objet d'une propriété incorporelle.

47_ـمرسوم تتفيذي 15-73 الذي يضبط الأحكام الخاصة بالنادي الرياضي المحترف، جر

العدد 11، لسنة 2015.

48_ أنظر الجريدة الرسمية عدد44 المؤرخة في 23 يوليو 2003 لسنة 2003. 
49- صالح فرحة زراوي: " الكامل في القانون التجاري، القسم الثاني الحقوق الفكرية" دون

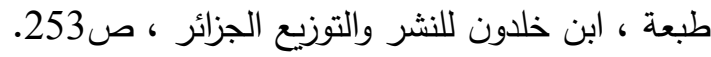

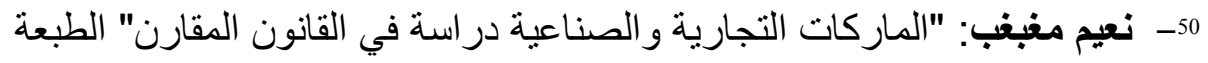

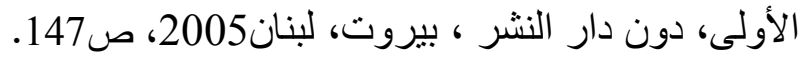

